
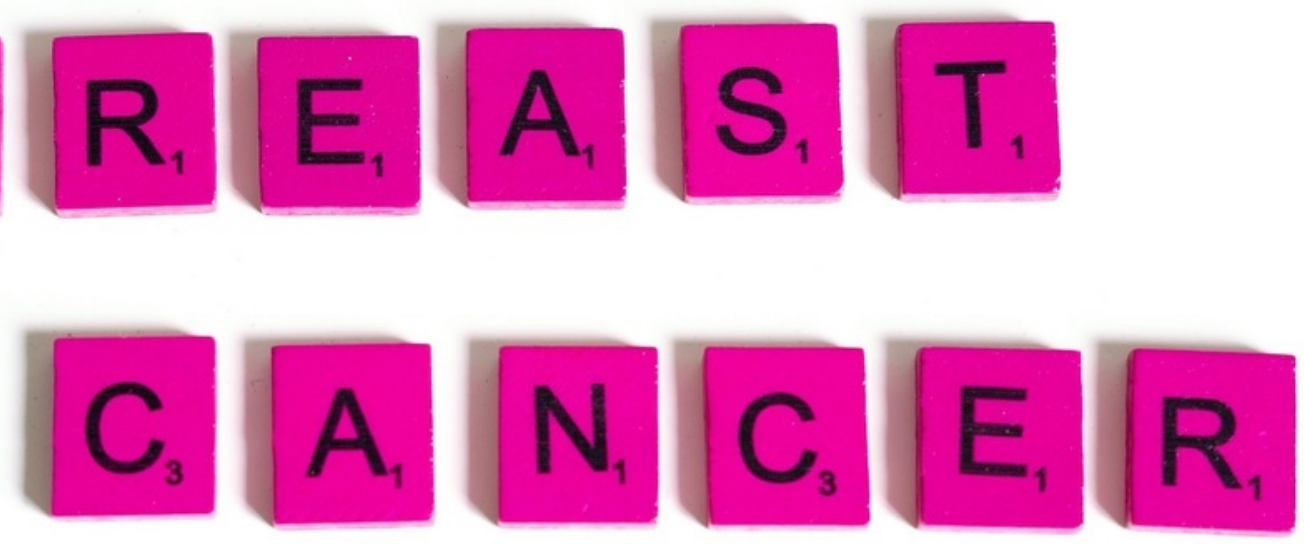

\title{
Evaluation of Chloroquine and Hydroxychloroquine Efficacy on Chemotherapy Treatment in triple negative Breast Cancer by continuous live Cell Imaging
}

\author{
Authors: Amina Poplata \\ Submitted: $\quad 25$. July 2021 \\ Published: $\quad$ 2. August 2021 \\ Volume: 8 \\ Issue: $\quad 3$ \\ Affiliation: Hochschule Furtwangen University, Furtwangen, Germany \\ Languages: English \\ Keywords: $\quad$ Cancer, Breast Cancer, Chemotherapy, Treatment, Demetrios \\ Award, Master Thesis \\ Categories: Demetrios Project, Humanities, Social Sciences and Law, \\ Medicine \\ DOI: $\quad$ 10.17160/josha.8.3.771
}

\section{Abstract:}

Triple negative breast cancer is heterogeneous type of breast cancer which, due to its high proliferation, aggressiveness, rapid progression and poor prognosis, is still a challenge to treat. These characteristics, together with distant metastasis, make this breast cancer subtype resistant to standard treatment. With the lack of targeted therapy, conventional chemotherapy is still the only established treatment option, where mostly taxanes and anthracyclines are chemotherapy of choice. Therefore, there is a need for investigation and development of new effective therapy regimens with goal to improve clinical therapy outcomes.

Recently, it has been reported that autophagy has a protective role in response to anti-tumor treatments in many cancer types, including breast cancer, leading to chemotherapy resistance and has gained

\section{JOSHA Jumana ostancese Humanities and Arts}



Fakultät Medical and Life Sciences

\section{Master-Thesis}

\section{Evaluation of Chloroquine and Hydroxychloroquine efficacy on chemotherapy treatment in triple negative breast cancer by continuous live cell imaging}

\section{Amina Poplata}

\section{MDT}

Prüfer

1. Prüfer - Prof. Dr. rer. nat. habil. Hans-Peter Deigner, HFU

2. Prüfer - Dr. Marie Follo, Universitätsklinikum Freiburg 



\title{
Title: \\ Evaluation of Chloroquine and Hydroxychloroquine efficacy on chemotherapy treatment in triple negative breast cancer by continuous live cell imaging
}

\section{Author: Amina Poplata}

1. Examiner: $\quad$ Prof. Dr. rer. nat. habil. Hans-Peter Deigner, HFU

\section{Examiner: $\quad$ Dr. Marie Follo, Universitätsklinikum Freiburg}

Semester: $\quad$ Summer Semester 2020

\begin{abstract}
:
Triple negative breast cancer is heterogeneous type of breast cancer which, due to its high proliferation, aggressiveness, rapid progression and poor prognosis, is still a challenge to treat. These characteristics, together with distant metastasis, make this breast cancer subtype resistant to standard treatment. With the lack of targeted therapy, conventional chemotherapy is still the only established treatment option, where mostly taxanes and anthracyclines are chemotherapy of choice. Therefore, there is a need for investigation and development of new effective therapy regimens with goal to improve clinical therapy outcomes. Recently, it has been reported that autophagy has a protective role in response to anti-tumor treatments in many cancer types, including breast cancer, leading to chemotherapy resistance and has gained significant interest in cancer research. Here, we assessed the role of autophagy inhibitors, chloroquine and hydroxychloroquine on MDAMB-231 TNBC cell line and chemotherapy drug efficacy in this cell line when these autophagy inhibitors were administrated in combination with chemotherapy, camptothecin and gemcitabine. The cell responses were observed by continuous live cell imaging, robust method that enables detection of dynamic morphological changes, thus providing better insights of complex cellular processes. Our data suggest that when MDA-MB231 cells were ptretreated with either $30 \mu \mathrm{M}$ chloroquine or $30 \mu \mathrm{M}$ hydroxychloroquine followed by chemotherapy drug administration, in this case gemcitabine and camptothecin, dead cell area was in significant increase, compared to drugs given as single agents. Moreover, even when chemotherapy drugs were administrated at lower doses after chloroquine and hydroxychloroquine pretreatment it followed the same pattern of significant dead cell area increase. These findings indicate potential anti-cancer effect of both chloroquine and hydroxychloroquine and suggest further clinical investigation of these autophagy inhibitors in combination with chemotherapeutics and in different cancer types due to their potential value in the development of novel cancer therapies.
\end{abstract}

Keywords: Triple negative breast cancer, live cell imaging, autophagy, apoptosis, chemotherapy, chloroquine, hydroxychloroquine 


\section{Eidesstattliche Erklärung}

Ich erkläre hiermit an Eides statt, dass ich die vorliegende Arbeit selbständig und ohne unzulässige fremde Hilfe angefertigt habe.

Alle verwendeten Quellen (Literatur, Internet) sind im Literaturverzeichnis vollständig zitiert.

Villingen-Schwenningen, den 1. November 2020

Adresse: Staufener Straße 29, 79115 Freiburg im Bresigau

Unterschrift: 



\section{Abstract}

Triple negative breast cancer is heterogeneous type of breast cancer which, due to its high proliferation, aggressiveness, rapid progression and poor prognosis, is still a challenge to treat. These characteristics, together with distant metastasis, make this breast cancer subtype resistant to standard treatment. With the lack of targeted therapy, conventional chemotherapy is still the only established treatment option, where mostly taxanes and anthracyclines are chemotherapy of choice. Therefore, there is a need for investigation and development of new effective therapy regimens with goal to improve clinical therapy outcomes. Recently, it has been reported that autophagy has a protective role in response to anti-tumor treatments in many cancer types, including breast cancer, leading to chemotherapy resistance and has gained significant interest in cancer research. Here, we assessed the role of autophagy inhibitors, chloroquine and hydroxychloroquine on MDA-MB-231 TNBC cell line and chemotherapy drug efficacy in this cell line when these autophagy inhibitors were administrated in combination with chemotherapy, camptothecin and gemcitabine. The cell responses were observed by continuous live cell imaging, robust method that enables detection of dynamic morphological changes, thus providing better insights of complex cellular processes. Our data suggest that when MDA-MB-231 cells were ptretreated with either $30 \mu \mathrm{M}$ chloroquine or $30 \mu \mathrm{M}$ hydroxychloroquine followed by chemotherapy drug administration, in this case gemcitabine and camptothecin, dead cell area was in significant increase, compared to drugs given as single agents. Moreover, even when chemotherapy drugs were administrated at lower doses after chloroquine and hydroxychloroquine pretreatment it followed the same pattern of significant dead cell area increase. These findings indicate potential anti-cancer effect of both chloroquine and hydroxychloroquine and suggest further clinical investigation of these autophagy inhibitors in combination with chemotherapeutics and in different cancer types due to their potential value in the development of novel cancer therapies. 



\section{Acknowledgements II}

I would like to express my appreciation to my supervisors, Prof. Dr. rer. nat. habil. Hans-Peter Deigner and Dr. Marie Follo, for their profound guidance throughout my scientific advancement. I would also like to thank Prof. Dr. Drs. h.c Roland Mertelsmann, for giving me the opportunity to be a part of his multidisciplinary team, to conduct my thesis and for his valuable advices, constructive suggestions and continuous support and encouragement during this thesis.

The daily work on this project could not be done without my colleagues from the LabmAIte team as well as the Core Facility at the the Zentrum Translationale Zellforschung at the Department of Internal Medicine I where me and my colleagues were able to perform our experiments at any time and on any day.

Last but not least, I would like to thank my family, friends and beloved ones for their unconditional support and encouragement throughout my studies and this thesis project. 



\section{List of Figures III}

Figure 1. Percentages of new cancer cases and cancer deaths worldwide in 2018.

Figure 2. Different stages of apoptosis.

Figure 3. Schematic representation of autophagy.

Figure 4. Autophagic process. CQ and HCQ inhibit autophagy through interference with the lysosomal acidification.

Figure 5. Examples of various dynamic processes that can be monitored and quantified in living cells by automated live-cell imaging.

Figure 6. MDA-MB-231 TNBC cell line.

Figure 7. Design of Falcon 96-well Clear Flat Bottom TC-treated Culture Microplate.

Figure 8. Design of an Ibidi $\mu$-Slide $4 \mathrm{Well} \mathrm{Ph}+$ Chip.

Figure 9. Incucyte ${ }^{\circledR}$ S3 Live-Cell Analysis System.

Figure 10. Propidium iodide (PI) intercalation in DNA of the dead cell.

Figure 11. MDA-MB-231 cellular responses in 96-well plate.

Figure 12. MDA-MB-231 cellular responses in 96-well plate after a different treatment strategy is applied.

Figure 13. Image analysis of TNBC MDA-MB-231 response to different treatment strategies followed for 48 hours.

Figure 14. MDA-MB-231 cellular responses in a 96-well plate after different treatment strategy were applied.

Figure 15. Image analysis of TNBC MDA-MB-231 response to different treatment strategies followed for 48 hours.

Figure 16. MDA-MB-231 cellular responses in a 96-well plate after different treatment strategy was applied. 
Figure 17. Image analysis of TNBC MDA-MB-231 response to different treatment strategies followed for 48 hours.

Figure 18. MDA-MB-231 cellular responses in a 96-well plate after different treatment strategy was applied.

Figure 19. Image analysis of TNBC MDA-MB-231 response to different treatment strategies followed for 48 hours.

Figure 20. MDA-MB-231 cellular responses in a 4-well plate after different treatment strategy was applied.

Figure 21. Image analysis of TNBC MDA-MB-231 response to different treatment strategies followed for 48 hours. 


\section{List of Tables}

Table 1. Therapeutic Options for the 3 Breast Cancer Subtypes. 



\section{List of Abbreviations and Symbols V}

IHC - Immunohistochemical

ER - Estrogen

PR - Progesteron

HER 2 - Human epidermal growth factor 2

TNBC - Triple negative breast cancer

BCL - Basal-cell like breast cancer

IM - Immunomodulatory breast cancer

M - Mesenchymal breast cancer

DFS - Disease-free survival

OS - Overall survival

BRCA - Breast Cancer gene

TP53 - Tumor protein p53

PTEN - Phosphatase and tensin homolog protein

AC - Adriamycin/cyclophosphamide

AC-T - Adriamycin/cyclophosphamid/paclitaxel (AC-T)

TC - Docetaxel/cyclophosphamide

TH - Paclitaxel/trastuzumab

AC-TH \pm P - Adriamycin/cyclophosphamide/ paclitaxel/trastuzumab \pm pertuzumab

$\mathrm{TCH} \pm \mathrm{P}$ - Docetaxel/carboplatin/trastuzumab \pm pertuzumab

pCR - Pathologic complete response

DNA - Deoxyribonucleic acid

PARP - poly ADP ribose polymerase

PI3K - Phosphoinositide 3-kinase

MEK - Mitogen-activated protein kinase

mTOR - Mammalian target of rapamycin

mCHT - Metronomic chemotherapy

MTD - Maximum tolerated dose 
Treg - Regulatory T cells

TNF - Tumor necrosis factor

PS - Phosphatidylserin

Bcl-2 - B-cell lymphoma 2

Bax - Bcl-2-associated X protein

IAPs - Inhibitor of apoptosis proteins

siRNA - Small interfering RNA

ATGs - Autophagy-related genes

ATP - Adenosine triphosphate

p62/SQSTM1- Ubiquitin-binding protein p62/Sequestrosome-1

BCSCs - Breast cancer stem cells

CQ - Chloroquine

HCQ - Hydroxychloroquine 


\section{Content}

Abstract

Acknowledgements

List of Figures $\quad$ III

List of Tables $\quad$ IV

List of Abbreviations and Symbols $\quad$ V

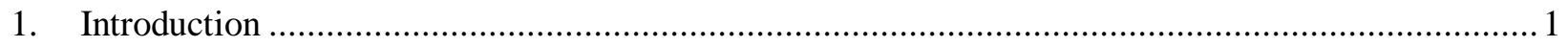

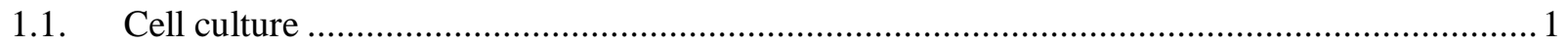

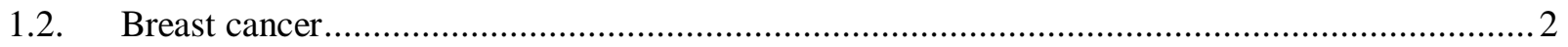

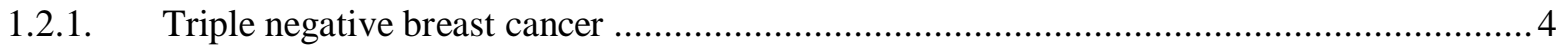

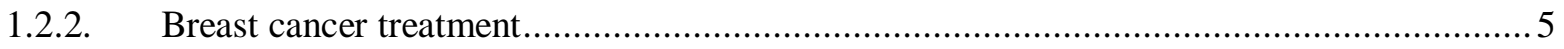

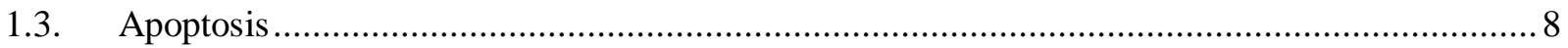

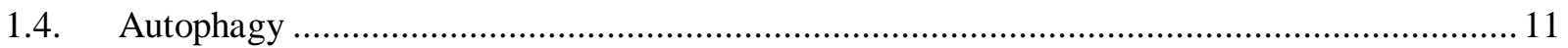

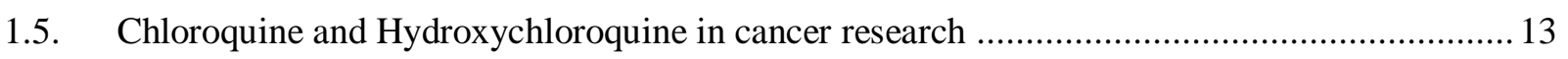

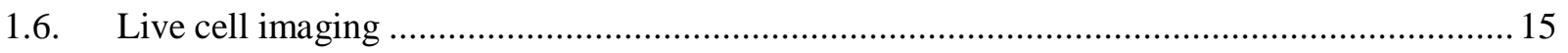

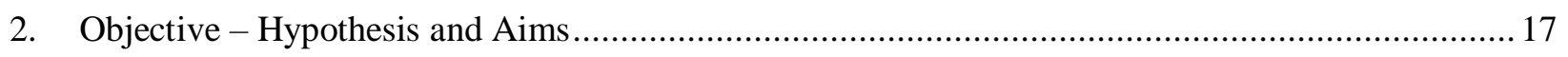

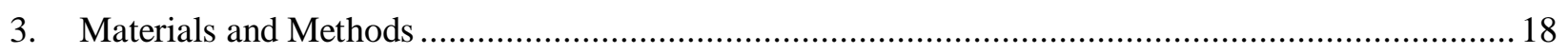

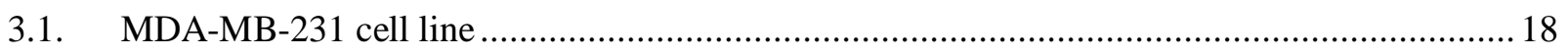

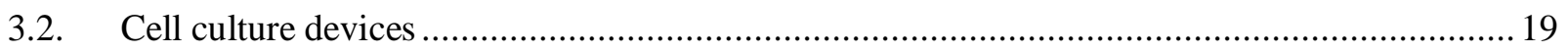

3.2.1. Falcon 96-well Clear Flat Bottom TC-treated Culture Microplate ................................ 19

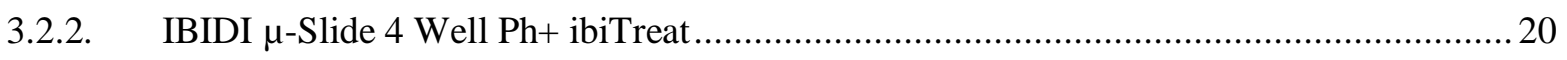

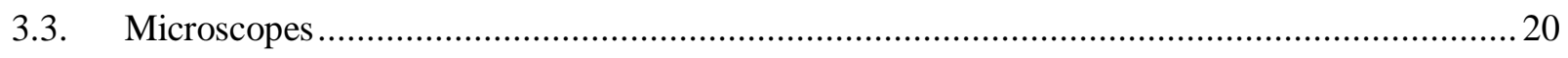

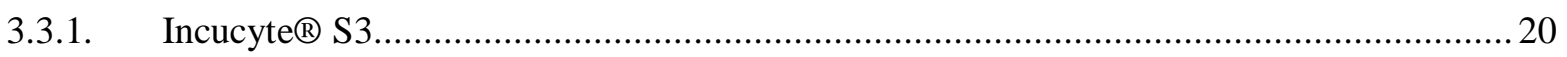

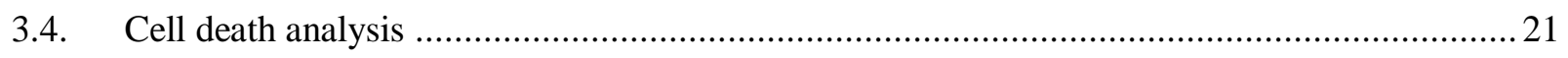

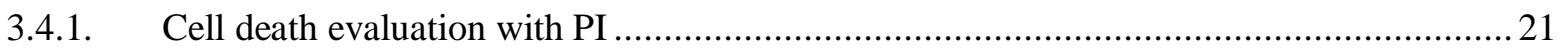

3.4.2. Chloroquine/Hydroxychloroquine and chemotherapy combination therapy evaluation in 96

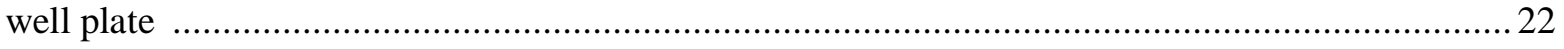

3.4.3. Chloroquine/Hydroxychloroquine and chemotherapy combination therapy evaluation in 4-

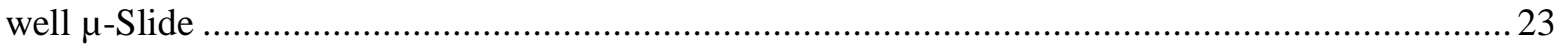

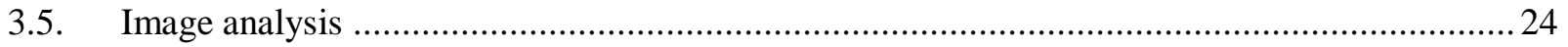

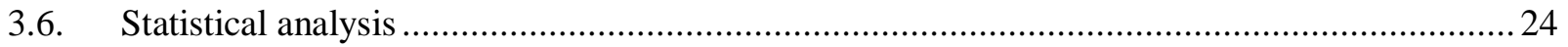

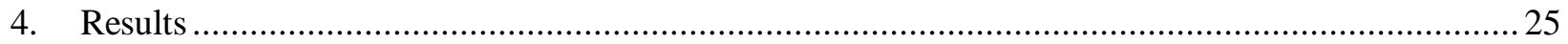

4.1. Effects of chloroquine, hydroxychloroquine, gemcitabine and camptothecin as single agents and in combination at higher concentrations 
4.2. Effects of chloroquine, hydroxychloroquine, gemcitabine and camptothecin as single agents and

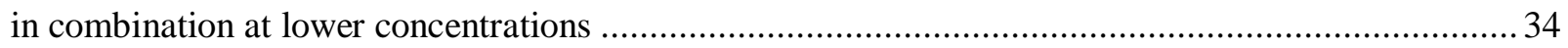

4.3. Effects of chloroquine, hydroxychloroquine and gemcitabine as single agents and in

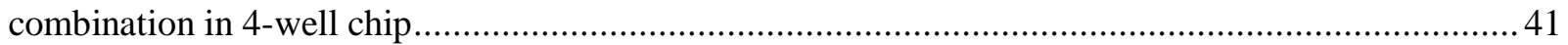

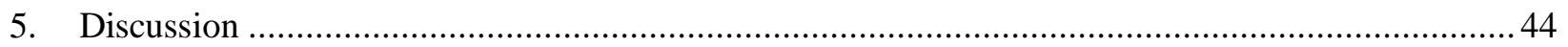

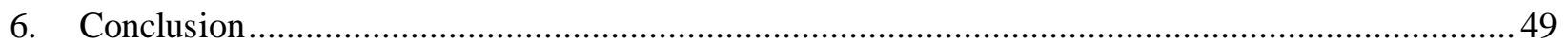

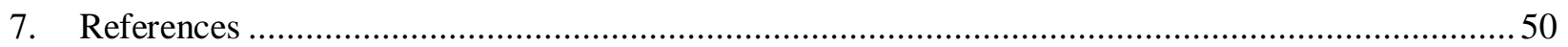





\section{Introduction}

\subsection{Cell culture}

Since its development in the early $20^{\text {th }}$ century, the cell culture system has become extremely useful approach for in vitro studies (1). With the improvement of the cell culture methods over the last few decades studying various mechanisms of cell behavior, function, growth and differentiation became successfully performed. Nowadays, there is a wide range of areas where cell culture techniques can be applied in order to better understand cell biology, mechanisms of diseases as well as development, effect and outcome of new drugs (2). Moreover, this approach is playing indispensable role in biotechnology production of monoclonal antibodies, vaccines and new treatment methods as preclinical model systems with possible expansion to personalized therapy strategies (3).

Cancer research is one of the fields where cell culture methods are used regularly. Discovery of the HeLa cell line isolated by George Gey at John Hopkins University Hospital in Baltimore in 1951 opened a wide range of possibilities in this field of research. HeLa is the first cancer cell line derived from women named Henrietta Lacks, who was diagnosed with cervical carcinoma (4). With its establishment and stabilization, HeLa cells became first human continuous cell line, making cell culture important experimental tool that enable scientists worldwide to gain deeper knowledge in the field of cancer (5). With the right approach and the choice of cell culture methods scientists are able to get insights into cancer biology, optimization and even discover of new therapy strategies (6) aiming to achieve personalized therapies.

Currently, the 2D cell culture method is mostly performed in the labs using Petri dishes, multiwell plates and culture flasks, although the 3D model is becoming popular due to aim of mimicking in vivo features in cell culture $(7,8)$. Nevertheless, $2 \mathrm{D}$ cultures are commonly used because of their performance, simplicity, reproducibility and easy interpretation (9), ability to form a culture within minutes to a few hours and low cost compared to 3D culture (8). 
Unfortunately, this cell culture approach has numerous limitations, disadvantages and drawbacks. As mentioned before, classical culture methodology, where cells are grown in monolayer, leads to inability to imitate in vivo cellular conditions, therefore producing morphologically and physiologically changed cell behavior which does not completely represent natural cellular microenvironment $(10,11)$. One possible solution and promising tool for providing desirable physiological and biological microenvironment is usage of microfluidic systems with desired perfusion strategy which allows continuous fresh media supply while removing metabolic products in addition to adding substances of interest such as chemotherapeutic drugs at different concentrations and with different schedules as well as drug combinations. Using this microfluidic system, with more relevant experimental methodology in terms of recreating unique microenvironment of cancer cells in vitro, makes it possible to monitor biological behavior under desired conditions. This approach has huge potential to predict different biological outcomes of resulting behavior, making progress in cancer treatment strategies (12).

\subsection{Breast cancer}

Cancer is referred to group of heterogeneous malignant diseases with ability to develop, grow and spread in different parts of the body. Main characteristic of every cancer is ability to grow uncontrollably. If these abnormal cells stars to evade other tissues and organs in the body without control, known as metastasis, it can cause cancer-related death. Recurrence and metastasis are major causes of death (more than $90 \%$ of cases) because of poor prognosis and treatment difficulty (13).

Breast cancer is the most prevalent malignancy in woman with $\sim 1.3$ million reported cases each year in the world. In terms of causes of death by cancer, it holds second position after lung cancer with 627,000 death cases that occurred only in 2018 (14) (Figure 1). Due to heterogeneity of breast tumors, with many diverse biological and pathological characteristics, that results in different behaviors, treatment responses are varying among patients, making it still a challenge to treat (15). Therefore, new treatment strategies are required. Knowing exact differences of these different behaviors and grouping them into specific subtypes is one step further to proper therapeutic approach since each subtype is responding differently to treatment (16). 

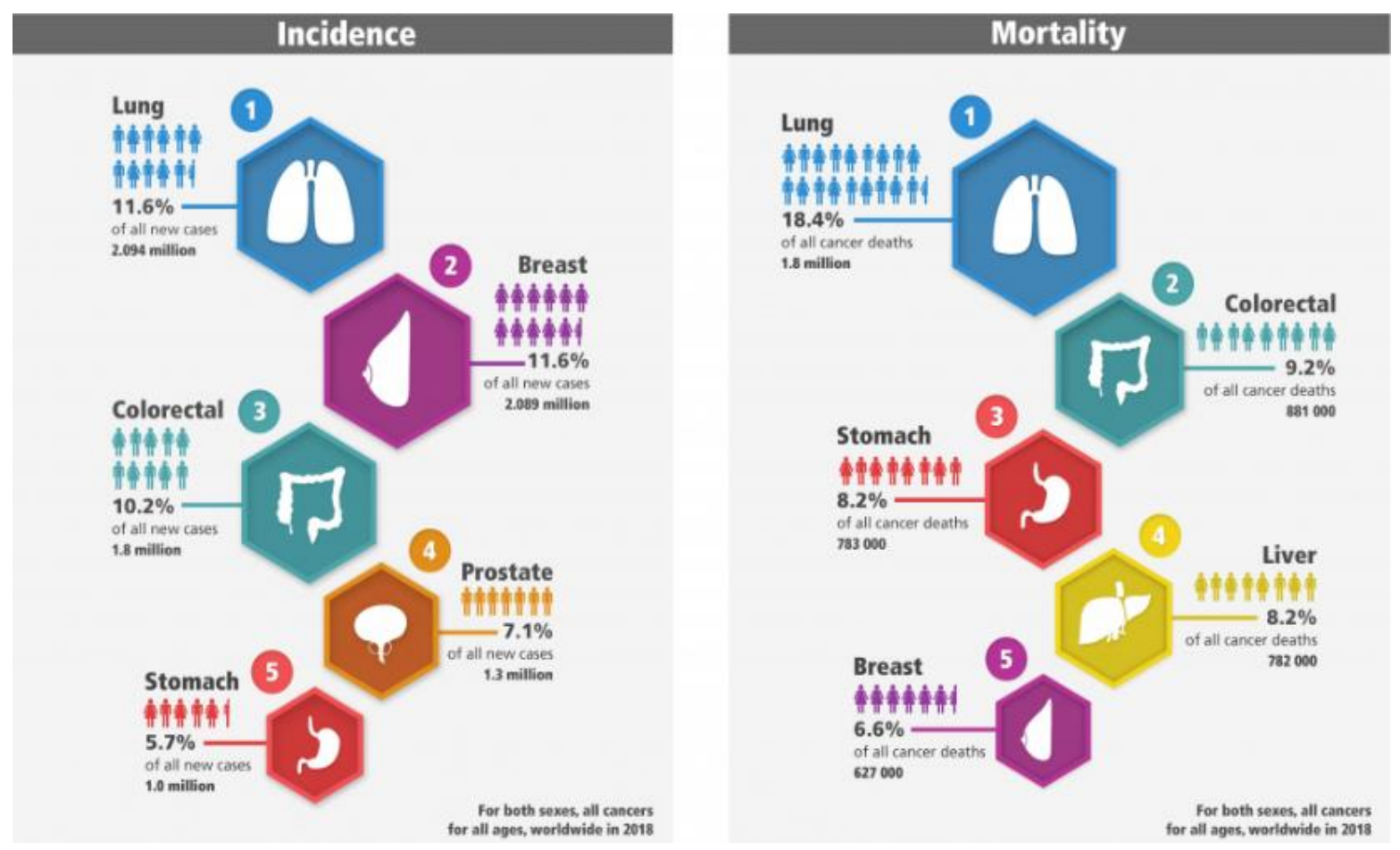

Figure 1. Percentages of new cancer cases and cancer deaths worldwide in 2018.

(Source: International Agency for Research on Cancer, GLOBOCAN 2018).

Based on presence or absence of classical immunohistochemical (IHC) breast tumor markers for estrogen (ER) or progesterone (PR) receptors and human epidermal growth factor 2 (HER2, now ERBB2) breast cancers are grouped into three major subtypes: hormone receptor-positive/ERBB2 negative (HR+/ERBB2-) with 70\% of cases, ERBB2 positive (ERBB2+) with $15-20 \%$ of cases, and triple-negative subtype (absence of all 3 molecular tumor markers) with $~ 15 \%$ of cases. All these subtypes have distinct clinical and pathological features and hence demand specific treatment strategies (17). With the development of microarray-based technologies the gene expression profiling has led to different classification approach of breast cancer based on molecular rather than morphological characteristics since there are various possible gene expression patterns in breast cancer leading to different treatment responses and prognosis. In 2000 Perou and Sorlie proposed molecular breast cancer classification with at least five main subtypes: luminal (A and B subtypes), ERBB2-over expression, basal cell-like (BCL) and normal- like. The inclusion of molecular classification in classical IHC breast cancer markers can provide more precise information in terms of each patient prognosis, relapse risk and probability for pathological complete response (18). 


\subsubsection{Triple negative breast cancer}

Triple-negative breast cancer (TNBC), refers to breast cancer subtype characterized by lacking in three main molecular targets presented on the surface of breast cancer cells - absence of ER and PR receptor expression as well as lack of amplification or overexpression of HER2 (ERBB2) (18). This heterogeneous BC subtype accounts for approximately 15-20\% cases of breast cancers, of which about $75 \%$ are "basal-like" (19). Basal-like TNBC is one of the six molecularly distinct TNBC subtypes that are defined based on their gene expression profiles (basal-like - BL1 and BL2; immunomodulatory - IM, mesenchymal - M, mesenchymal stem-like - MSL, and luminal androgen receptor - LAR subtype) all of which have distinct biological pathways and prognosis. The importance of researching this cancer group is due to unfavorable prognosis with shorter disease-free survival (DFS) and overall survival (OS), its aggressiveness and high risk of both local and distant relapses in first 3 to 5 years after diagnosis, and therapy resistance (20). Recurrence is found in 50\% of patients in the early stage of disease and 5-year mortality rate after surgery is presented in $37 \%$ of patients (21). TNBCs metastasize mostly to the lungs and the central nervous system, which differs from non-TNBCs where bones are usually metastatic target. Those patients with this aggressive metastatic stage have shorter progression-free survival (PFS) after chemotherapy failure (22).

TNBC is found to be more frequent in young women (under 40 years old) (23) and women of specific ethnic groups (African-American and Hispanic) (20). Furthermore, mutation or abnormal expression of BRCA (Breast Cancer gene) genes is also significantly associated with TNBC since more than $75 \%$ of breast cancer cases with BRCAl/2 mutations are characterized with TNBC phenotype, which can have an impact on sensitivity to chemotherapy treatment that possess DNAdamaging effect (e.g. platinum-based agents) $(24,25)$. TP53 (tumor protein p53) and PTEN (phosphatase and tensin homolog) genes are also found to be most frequently mutated or lost in TNBC (26).

All this show that therapy failure and limited treatment options are challenging problem. Therefore, improvement of current treatment approaches and chemotherapy combinations with targeted therapy is necessary in case of TNBC. 


\subsubsection{Breast cancer treatment}

In case of breast cancer that are not metastatic, primary goal is to prevent metastatic development. Local therapy refers to removing the cancer from the local area (in the case of breast cancer these are breast and axillary lymph nodes) and includes surgery which may or may not include radiation therapy. On the other hand, neodjavunat and adjuvant systematic therapy administration depends on diagnosed breast cancer subtype (Table 1.) (17).

Table 2. Therapeutic Options for the 3 Breast Cancer Subtypes. (17)

\section{(HR)+/ERBB2- ERBB2+ (HR+ or HR-) \\ Triple negative}

$\begin{array}{lll}\text { Pathological } & \geq 1 \% \text { Of tumor cells stain positive for } & \text { Tumor cells stain strongly (3+) for ERBB2 } \\ \text { definition } & \text { estrogen receptor or progesterone } & \text { protein or ERBB2 gene is amplified in tumor } \\ & \text { receptor proteins } & \text { cells. } \\ & & \text { Approximately half of ERBB2+ tumors are } \\ & \text { also HR+. }\end{array}$

Endocrine therapy (all patients):

- Tamoxifen, letrozole,

Typical

systemic

therapies for

non

metastatic

disease

(agents,

route, and

duration) anastrozole, orexemestane

- Oraltherapy

Chemotherapy(some patients):

- Adriamycin/cyclophosphamide (AC)

- Adriamycin/cyclophosphamid/p aclitaxel (AC-T)

- Docetaxel/cyclophosphamide (TC)

- Intravenoustherapy

- 12-20 wk
- 5-10 y
Tumor does not meet any pathologic criteria for positivity of estrogen receptor, progesterone receptor, or ERBB2

Chemotherapy + ERBB2 targeted therapy (all patients):

- Paclitaxel/trastuzumab (TH)

- Adriamycin/cyclophosphamide/ paclitaxel/trastuzumab \pm pertuzumab (AC-TH $\pm \mathrm{P})$

- Docetaxel/carboplatin/trastuzumab \pm pertuzumab $(\mathrm{TCH} \pm \mathrm{P})$

- Intravenous therapy

- 12-20 wk of chemotherapy;

- 1 y of ERBB2-targeted therapy Endocrine therapy (if also hormone receptor positive):

- Tamoxifen, letrozole, anastrozole, orexemestane

- Oral therapy

- $5-10 \mathrm{y}$
Chemotherapy (all patients):

- $\mathrm{AC}$

- $\mathrm{AC}-\mathrm{T}$

- $\mathrm{TC}$

- Intravenous therapy

- $12-20 \mathrm{wk}$ 
Hence, for $\mathrm{HR}+/ \mathrm{ERBB} 2$ - breast cancer endocrine therapy is the primary choice of treatment, which blocks tumor growth by impairing estrogen function as well as lowering its level. Some of the drugs used for this purpose are tamoxifen, aromatase inhibitors (letrozole, anastrozole, and exemestane), gonadotropin-releasing hormone agonists (goserelin and leuprolide acetate). Five years of estrogen therapy is considered as standard treatment that reduces recurrence (by $\sim 50 \%$ ) and leads to OS rate improvement $(17,27)$, although it has been reported that longer estrogen therapy administration, up to 10 years, leads to even better response (28). Because all these drugs have different effects on cancer cells, combining endocrine drugs, sometimes also with chemotherapy, is recommended for better effectiveness $(17,27)$. Due to the possibility of developing resistance, researchers are now working on the development of new therapeutic strategies, with major focus on the endoplasmic reticulum (ER)-related pathways, like the PI3KAkt-mTOR and CDK4/6 pathways, since genes involved in those pathways are mostly mutated in HR+/ERBB2- breast cancer and may contribute to endocrine therapy resistance (29).

Anti-ERBB2 targeted therapy, in combination with chemotherapy, is typically applied treatment approach in case of ERBB2+ breast cancers (27). After this treatment regimen administration, surgery, radiation and additional anti-ERBB2 targeted therapy is performed. Since the development of first targeted anti-ERBB2 therapy, trastuzumab, in 1998, improvement in OS has significantly improved, especially in case of metastatic stage of disease (28). Since trastuzumab resistance is being reported, both primary and acquired, the need for new drugs emerged. Some of these new agents include trastuzumab pertuzumab, ado- trastuzumab emtansine as well as tyrosine kinase inhibitor lapatinib (30). The chemotherapy combination of anthracycline and taxane is shown to be most effective in high risk patients, whereas all other combination regimens (shown in Table 1.) are considered to be a good choice for patients with lower risk (31).

Due to its poor prognosis, heterogeneity, aggressiveness and lack of target receptors (ER, PGR, and ERBB2) treating TNBC is still clinical challenge. In this BC subtype administration of chemotherapeutic agents, individually or in combination with surgery, is usually applied. Although this BC has a better response to chemotherapy than other BC subtypes, recurrence and metastasis are likely to happen (32). Pathologic complete response (pCR), is usually not achievable when treating patients with chemotherapy, so there is a need for profound treatment research and selection. pCR is considered to be an important prognostic marker in TNBC treated with neoadjuvant chemotherapy since some studies show that neoadjuvant therapy, mostly with taxanes 
and anthracyclines, is related with higher pCR compared to non-TNBC (33). Recently, platinum based chemotherapeutic agents have gained popularity in TNBC treatment since BRCA1 mutation and its pathway is related to DNA repair mechanism impairment in some TNBC. The main mechanism of these drugs is DNA-crosslinking and activation of DNA repair mechanism that leads to apoptosis induction, which leads to higher sensitivity to platinum-based agents according to some preclinical and data. Therefore, adding platinum-based agents to neoadjuvant treatment, despite the toxicity, should be considered as a promising treatment option $(17,34)$. Personalized therapy is considered to be the most effective approach to treat patients with this breast cancer subtype, mainly those who fail in chemotherapy response or express chemotherapy resistance. Numerous studies are currently working on the molecular targets detection, which could be efficiently targeted in TNBC either as single drugs, or they could have a significant role in overcoming chemotherapy resistance. Since most of TNBCs that fail in chemotherapy treatment response have alteration in pathways, development of these targeted chemotherapy agents for targeting these altered pathways could lead to enormous improvements in the treatment of highly resistant forms of TNBC. Some of these agents are PARP inhibitors, PI3K inhibitors, MEK inhibitors, mTOR inhibitors (35).

Even though progress has been made in terms of understanding cancer biology and mechanism of various chemotherapy drugs, dose and schedule of administration of these agents are considered to be very important for chemotherapy efficiency, since toxic effects and chemotherapy resistance are still major problem in cancer treatment. Therefore, a new schedule of administration, known as metronomic chemotherapy $(\mathrm{mCHT})$ has recently gained attention as currently most effective treatment option, especially in high-risk group of patients and those with metastatic form of cancer. mCHT refers to frequent and continuous administration of the minimum effective dose of conventional chemotherapeutic drugs, with minimal between-dose intervals that leads to enhanced antitumor efficacy with very low toxicity and minimal adverse effects that targets endothelial and cancer cells that are in a stage of proliferation. This approach differs from the standard chemotherapy regimen, where maximum tolerated dose (MTD) is used in 2-3 weeks intervals. MTD will kill tumor cells that are sensitive to chemotherapy, but also will negatively affect and kill healthy blood vessels, stromal cells including native immune responders. This approach has led to re-growth of cancer cells as well as the growth of clones with resistance to chemotherapy, 
so that after the first few cycles there is a possibility for development of the metastatic cancer stage without therapeutic response $(36,37,38)$.

mCHT has multiple mechanisms of action with effects on cancer cells as well as their microenvironment via tumor angiogenesis inhibition, stimulation of the anticancer immune response by suppressing immune regulatory cells (Treg) and tumor dormancy induction (39). Data from preclinical and clinical studies indicate that $\mathrm{mCHT}$ is promising therapy regimen for different tumors, including breast cancer, with the further aim to optimize this treatment strategy for successful clinical use.

\subsection{Apoptosis}

In order to maintain homeostatic balance in multicellular organisms, cells constantly grow, divide, differentiate and those that are damaged and unwanted are being removed through highly conserved programmed cell death known as apoptosis. Also, this process is part of many physiological conditions as it occurs normally during development and aging as well as in immune reactions. Cell death, especially apoptosis, is one of the most studied process among scientists since pathogenesis of many diseases, including cancer, are related to deficient or excessive level of cell death (40). Therefore, understanding the apoptosis pathways and regulation is necessary for better understanding of diseases and the development of new therapeutic strategies.

Apoptosis is characterized by multiple morphological changes (Figure 2.), that includes cell shrinkage, chromatin condensation (pyknosis) followed by plasma membrane blebbing and nucleus fragmentation (karyorrhexis) leading to the formation of apoptotic bodies. These bodies contain different cell organelles, with or without nucleus fragments, tightly folded inside an intact plasma membrane and signals that attract phagocytic cells are released. Macrophages or neighboring cells then detect and engulf apoptotic bodies by phagocytosis that are then degraded within phagolysosomes. Since the cells that undergo apoptosis do not release any cellular components into extracellular fluid nor produce anti-inflammatory cytokines and due to rapid phagocytosis, there is no inflammation within an apoptotic process. This is one of the main differences of apoptotic and necrotic cell death, since necrosis causes inflammation $(40,41,42)$. 


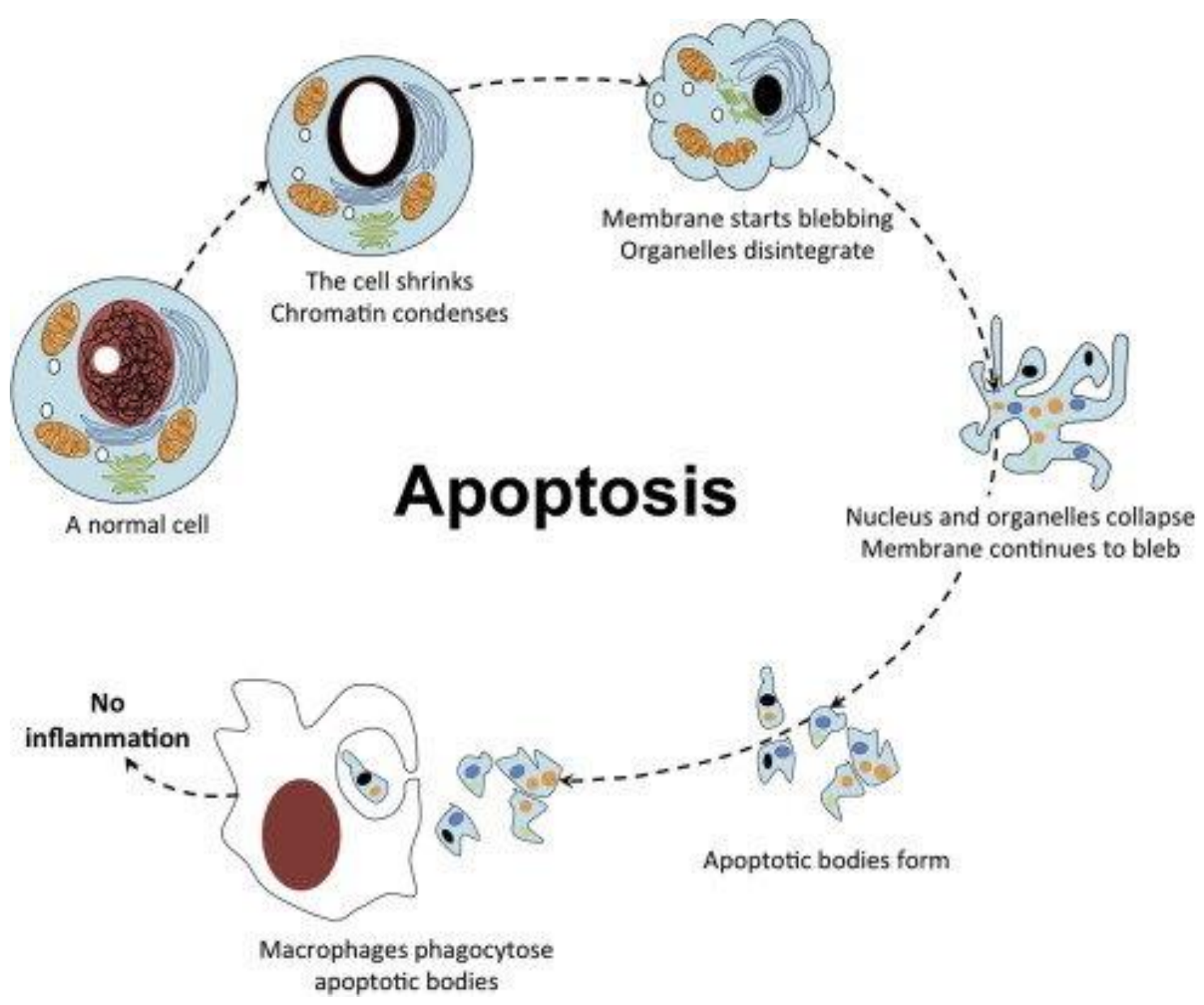

Figure 2. Different stages of apoptosis. (43)

Various enzyme-dependent biochemical processes occur during apoptosis: caspases activation, DNA breakdown, membrane changes and phagocytic recognition. Caspases are a family of cysteine proteases which can activate themselves as well as other caspases, leading to initiation of proteolytic cascade. These enzymes possess proteolytic activity, ability to cleave proteins at aspartic acid residues and the ability to activate DNAase for further DNA degradation. Caspases involved in apoptosis are categorized into initiators (caspase-2,-8,-9,-10), effectors or executioners (caspase-3,-6,-7) and inflammatory caspases (caspase-1,-4,-5) (44). There are two major apoptotic pathways by which caspases are activated. Mitochondrial (intrinsic) pathway starts in mitochondria where intracellular signals (free radicals, toxins, radiation, hypoxia and the absence of certain growth factors are produced in response to severe cellular stress. This leads to mitochondrial transmembrane potential and increased mitochondrial permeability, release of pro- 
apoptotic proteins into the cytoplasm which activate caspase-dependent mitochondrial pathway by activating caspase-3 and -9. Second pathway is death receptor (extrinsic) pathway, where death ligands are binding to a death receptor, usually members of the tumor necrosis factor (TNF) receptors, such as type 1 TNF receptor (TNFR1) and Fas receptor, resulting in the death signal transmitted from the cell surface to intracellular signaling pathways. These death signals also lead to the recruitment of adapter proteins from cytoplasm which are then associating and activating caspase-8. Both pathways are resulting in the execution phase, the final phase of apoptosis where execution caspases are activated, and morphological changes occur. Although caspase activation is a biochemical process characteristic for apoptosis, this type of cell death can be caspaseindependent. Macrophages can recognize dead cells at the early stage and rapidly phagocyte them with minimal effect on surrounding tissue. This is possible due to expression of phosphatidylserine (PS) in the outer layers of the plasma membrane, which is normally facing inner cell membrane bilayer. Phosphatidylserine is one of the cell surface markers that is presented on cell surface and recognized by macrophages $(40,42,44)$.

Evasion of apoptosis is one of the six distinctive biological capabilities of cancer, known as cancer hallmarks, which result in damaged cell accumulation causing uncontrolled cancer cell growth and malignant transformation. There are few mechanisms which results in apoptosis evasion and carcinogenesis: decreased caspase activity, changes in pro-apoptotic (usually down-regulated) and anti-apoptotic (usually up-regulated and overexpressed) proteins that causes impaired balance between them and damaged signaling in death receptors (45). Cancer cells can also acquire resistance to apoptosis, when pro-apoptotic proteins, such as Bax, are mutated or down-regulated or due to the over-expression of anti-apoptotic proteins, such as Bcl-2. Cell signaling pathways can also be defected leading to apoptosis dysregulation and cancer formation. The p53 tumor suppressor gene is an important cell cycle regulator that, if damaged, severely reduces tumor suppression. This gene is mutated in more than $50 \%$ of all human cancers. The inhibitor of apoptosis proteins (IAPs) are also involved in regulation of apoptosis, which act as endogenous inhibitors of caspases. Abnormal expression of these proteins is found in many cancers and can lead to chemotherapy resistance. Impairments in the death signaling pathways, such as receptor downregulation or defected function and reduced death signal levels are found to be responsible for apoptosis evasion and, based on some studies, can lead to acquired drug resistance $(45,46,47)$. 
Apoptosis-targeting therapies, used in combination with other chemotherapy drugs, with a focus on targeting the caspase cascade (small molecules that act as caspase activators or caspase-3 gene therapy), Bcl-2 family proteins (anti-Bcl-2 small molecules or silencing the anti-apoptotic genes and proteins by Bcl-2 specific siRNA) as well as other factors associated with apoptosis signaling are experiencing significant progress thus becoming promising cancer therapeutics $(45,48)$.

\subsection{Autophagy}

Autophagy has gained notable interest in cancer research and has recently become a potential anticancer target, although its role in cancer is still not completely understood. This cellular process is described as a highly conserved catabolic mechanism, tightly controlled by autophagyrelated genes (ATGs) and important for cellular homeostasis and damage control by which misfolded proteins, dysfunctional/long-lived organelles, intracellular pathogens and all other unnecessary macromolecules are removed (49). Under various stress conditions, including oxidative and metabolic stress, nutrient deprivation and hypoxia it enables proper energy balance through ATP generation and cell survival for both normal and cancer cells, therefore having a significant role in tumorigenesis.

During autophagy, targeted macromolecules are sequestrated into phagophore (preautophagosomal structure), double membrane vesicle formed from the endoplasmic reticulum, Golgi or mitochondria. When this structure is expanded, upon autophagy activation, it engulfs intracellular cargo leading to autophagosome formation (Figure 3). Autophagy is facilitated by an autophagosome cargo protein, p62/sequestosome 1 (SQSTM1) that binds to targeted intracellular macromolecules and ATGs mediate further steps of p62/SQSTM1-tagged cargo destruction (49). Once loaded with this cargo, autophagosome fuses with lysosome and forms autophagolysosme. Lysosomal fusion facilitates the degradation of nonfunctional cellular components by lysosomal acid proteases (50). 


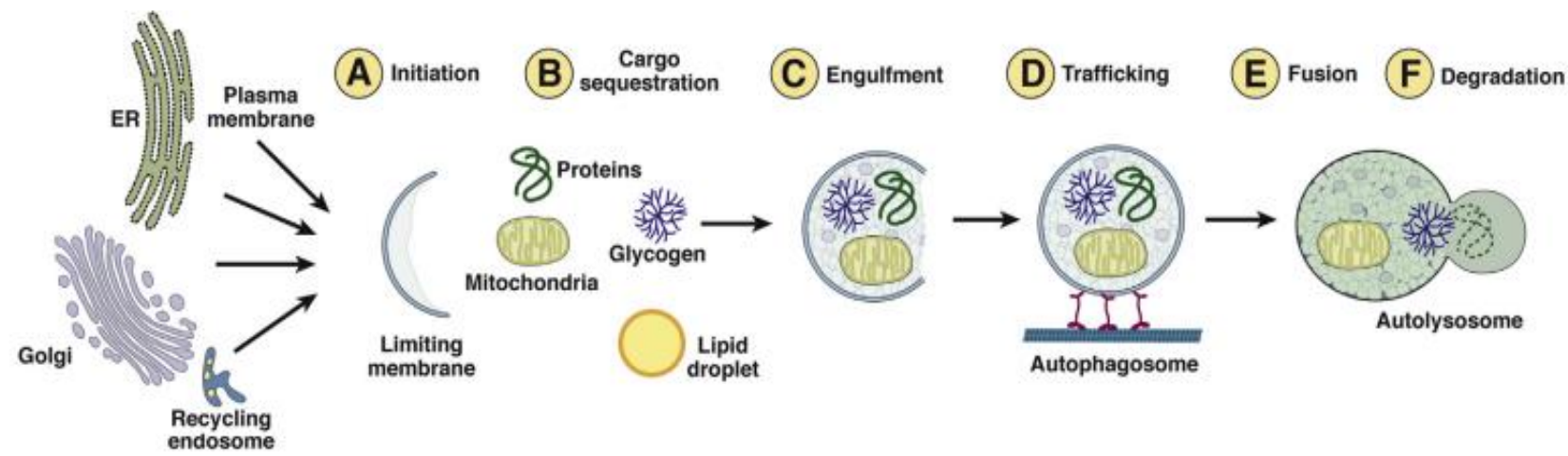

Figure 3. Schematic representation of autophagy. (A) Formation of isolated, limited membrane followed by (B) cargo sequestration that can occur in bulk or in a selective manner mediated by soluble protein receptors. After engulfment $(C)$, the autophagosome traffics $(D)$ via microtubules and delivers cargo to lysosomes through membrane fusion $(E)$ to form an autolysosome where cargo is degraded by lysosomal hydrolases $(F)$. (51)

The involvement of some tumor suppressor genes, such as Beclin-1 and PTEN in the autophagy process indicates that autophagy plays significant role in malignant transformation. It has been found that loss or low expression of beclin-1, which is involved in autophagy induction and progression, leads to tumor formation in different cancer types, including breast cancer (52). Although autophagy is found to be slowing down tumor growth in the initial phase of tumor growth and development, when primary tumors and metastases are developed this process has tumorpromoting role. Indeed, in breast cancer, autophagy is involved in drug resistance and metastasis, where it is found to be a crucial mechanism for survival of disseminated dormant tumor cells, known as breast cancer stem cells (BCSCs), cells with unlimited self-renewal and migratory properties that initiate tumor growth during tumor recurrence and metastatic dormancy (53).

Therefore, it has been proposed that triggering autophagy can be a potential cancer treatment strategy, since some cancer cell lines are responding to chemotherapy drugs when autophagy is triggered. Moreover, since chemotherapy resistance is still a major concern when treating different types of cancer, including breast cancer, autophagy inhibition is proposed as a mechanism that sensitize cells to chemotherapy and helps in overcoming resistance. Autophagy inhibitors, such as chloroquine and hydroxychloroquine, in combination with chemotherapy had gained interest as a potential cancer treatment strategy. Although autophagy in cancer is generally considered to have protective role and enhance evasion of apoptosis, due to lack of reliable biomarkers for better understanding if autophagy is having tumor-promoting or suppressing role in different cancer 
types there is a need for further studies to better understand the correlation between autophagy and current therapies and their potential effects $(54,55)$.

\subsection{Chloroquine and Hydroxychloroquine in cancer research}

The chloroquine family of drugs, chloroquine (CQ) and hydroxychloroquine (HCQ), are 4aminoquinoline-based drugs that has been widely used for the prophylaxis treatment of malaria. Due to their anti-inflammatory and immunosuppressive properties these drugs are used for treatment of rheumatoid arthritis, systemic lupus erythematosus, and Sjögren syndrome (56). HCQ was developed after chloroquine, as its analogue, by the addition of the hydroxyl group into CQ which resulted in a significant toxicity decrease ( 40\%) (57). In a project named "The Repurposing Drugs in Oncology" the importance of potential utilization of some already known and described non-cancer drugs for treating cancer is described. Among many drugs, CQ and HCQ are mentioned as drugs with potential ability to make cancer cells more sensitized to chemotherapy (58).

CQ and HCQ are lipophilic and amphiphilic weak bases which at the physiological pH of 7.4 are not protonated and have high ability to penetrate the membrane. As these compounds enter the cell, they are trapped in acidic organelles, with $\mathrm{pH}$ between 4-5, and there they become protonated. This protonated form leads to intra-organellar $\mathrm{pH}$ raise inside these organelles which affects the function of endosomes, lysosomes, autophagosomes, and autophagolysosomes. Because of its high affinity for lysosomes, CQ and its analogues predominantly accumulate in this organelle, becomes protonated, increase lysosomal pH thus inhibiting the lysosomal degradative enzymes (Figure 4). This fusion of lysosome and autophagosome and subsequent degradation of autophagolysosome which occurs in the latter stage of autophagy (59). 


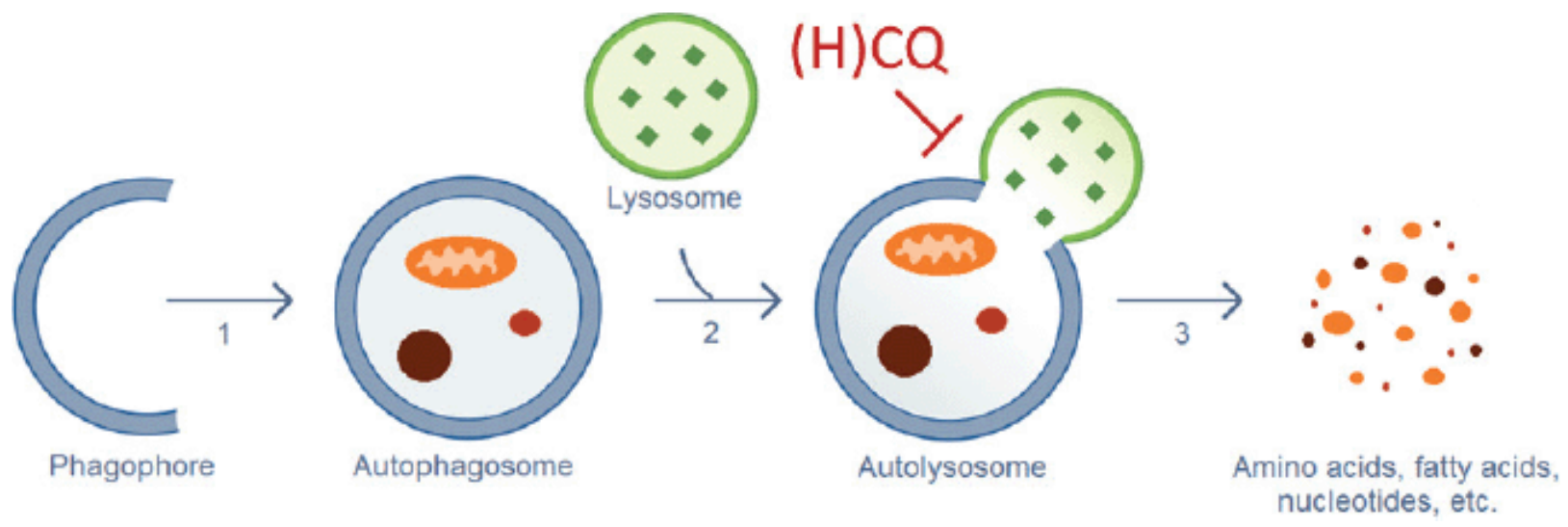

Figure 4. Autophagic process. $C Q$ and HCQ inhibit autophagy through interference with the lysosomal acidification (Step 2). (61)

Since autophagy promotes cancer survival as well as induces chemotherapy resistance, inhibition of lysosomal acidification, thereby inhibition of autophagy, by CQ is found to sensitize many cancer cells to the antiproliferative effect of radiation and chemotherapy, such as cisplatin, 5fluorouracil and oxaliplatin and increase the intracellular targets of drugs (60). Because of this ability to suppress autophagy CQ and its derivate became an important subject in cancer research as anticancer targets and cancer-specific chemosensitizers thus increasing effectiveness of cancer therapies.

Another reported anticancer effects of CQ and its derivate are cell-cycle arrest and apoptosis induction, p53 stabilization and activation of p53-dependent transcription of proapoptotic genes (61). Moreover, it has been reported that CQ leads to vascular normalization which is important for metastasis reduction, tumor hypoxia decrease and improvement of drug delivery and response (62).

Although many preclinical studies have reported beneficial effects of CQ, applied as single treatment agent, drug dose, tumor type, and other study parameters significantly vary between these studies, making it difficult to interpret the results. Numerous preclinical studies with these agents, usually in combination with other chemotherapy drugs, have been performed, both in vivo and in vitro and, due to its highly safe profile, they are recommended to be used as part of combination therapy with other chemotherapy agents. The vast majority showed improved therapeutic outcome, when only single chemotherapy drug is applied, due to CQ and HCQ ability to block pro-survival autophagy and enhance drug effectiveness (61). Many clinical trials with this 
setup have been performed with some of them still ongoing, since, currently, these two drugs are only two autophagy-inhibiting agents that are studies in clinical trials in solid tumors. Some of these trials reported tumor shrinkage, although others did not achieve that outcome, possibly because CQ and HCQ did not reach the effective concentration in the patient's plasma (63). Major focus of most completed clinical trials was addressing how safe and tolerable are CQ and HCQ in cancer where these drugs are found to be safe and tolerable, which, together with preclinical data that indicated positive anti-cancer effects, strengthen the idea of utilizing these drugs in cancer treatment (61).

\subsection{Live cell imaging}

Live-cell imaging is a well-established analytical tool in various biomedical research disciplines. The ability to follow a biological process, such as cell-cell interactions, inter- and intracellular transport, cytotoxic compound uptake, and protein-protein interaction of single molecules in living cells and tissues, has gained great interest over the last decade, as it provides the extra dimension of "real time." The main factors for successfully performed live-cell imaging are achieving image quality and maintaining cell health. However, different synthetic fluorophores or fluorescent proteins are often used in live-cell imaging experiments, which can require strong light to excite the fluorophores that can lead to photodamage and phototoxic side effect in live samples. Therefore, short exposure times, lower light source intensity and longer excitation wavelengths are recommended. In order to obtain meaningful data in live-cell imaging experiments, monitoring temperature, $\mathrm{CO} 2$ level, media composition and humidity are crucial, since cultured cells require conditions as close to physiological norms as possible. Nowadays, with technology advancement, small stage-top incubators, large boxes in which whole microscope is placed, environmental chambers are developed for achieving optimal conditions of live-cell imaging experiments. Currently, fourth dimension (time-lapse) imaging is widely used method for monitoring different biological processes can be monitored over an extended period of time, from just a few seconds to several weeks or even months (Figure 5.) $(64,65)$. 


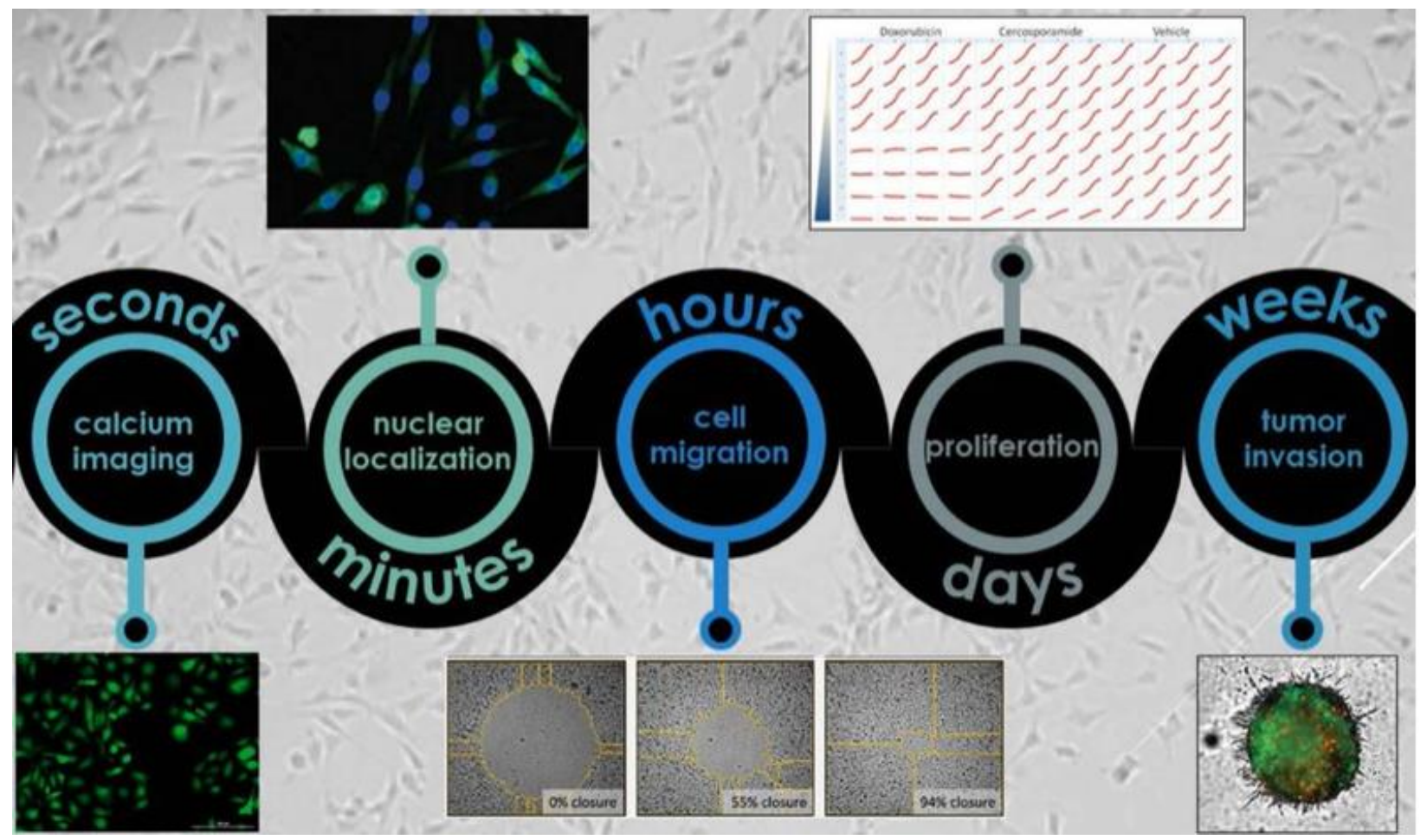

Figure 5. Examples of various dynamic processes that can be monitored and quantified in living cells by automated live-cell imaging. (66)

Live-cell imaging found its application in target and drug discovery where it can be extremely useful for kinetic studies of the drug's mechanism of action as well as closely mimic in vivo cellular responses instead of standard approach where fixed cells that requires staining and endpoint assays are used (67). The latest advances in live-cell imaging techniques makes this approach powerful tool for studying various dynamic molecular processes and tracking cellular behavior as well as drug responses that enables gaining deeper insight into the whole mechanism of disease development, uncovering precise drug's mode of action and quantification of drug responses that may provide new insight into old drugs (68). 


\section{Objective - Hypothesis and Aims}

Aim - Examination of chemotherapy drug efficacy on Triple Negative Breast Cancer (TNBC) cell line (MDA-MB-231) in combination with chloroquine and hydroxychloroquine by automated continuous live cell imaging.

Objectives:

- Detect and evaluate cell death in TNBC MDA-MB-231 when treated with combination of chloroquine/hydroxychloroquine and chemotherapy drug.

- Evaluate the efficacy of chosen chemotherapy drugs on TNBC MDA-MB-231 in comparison with chloroquine/hydroxychloroquine pretreated TNBC MDA-MB-231.

- Define imaging parameters for image analysis. 


\section{Materials and Methods}

\subsection{MDA-MB-231 cell line}

The MDA-MB-231 breast cancer cell line (Figure 6.) is an epithelial-like, human breast cancer cell line with a spindle-shaped phenotype and a doubling time of 35-40 hours. Since it lacks ER, PR expression and HER2 (ERBB2) amplification, the MDA-MB-231 breast cancer cell line is being characterized as TNBC with extreme aggressiveness, invasiveness and lack of differentiation. This TNBC cell line was obtained from a pleural effusion of a 51-year-old Caucasian female patient that was diagnosed with metastatic mammary adenocarcinoma and is one of the most frequently used cell lines in cancer research and drug development, both in vitro and in vivo.

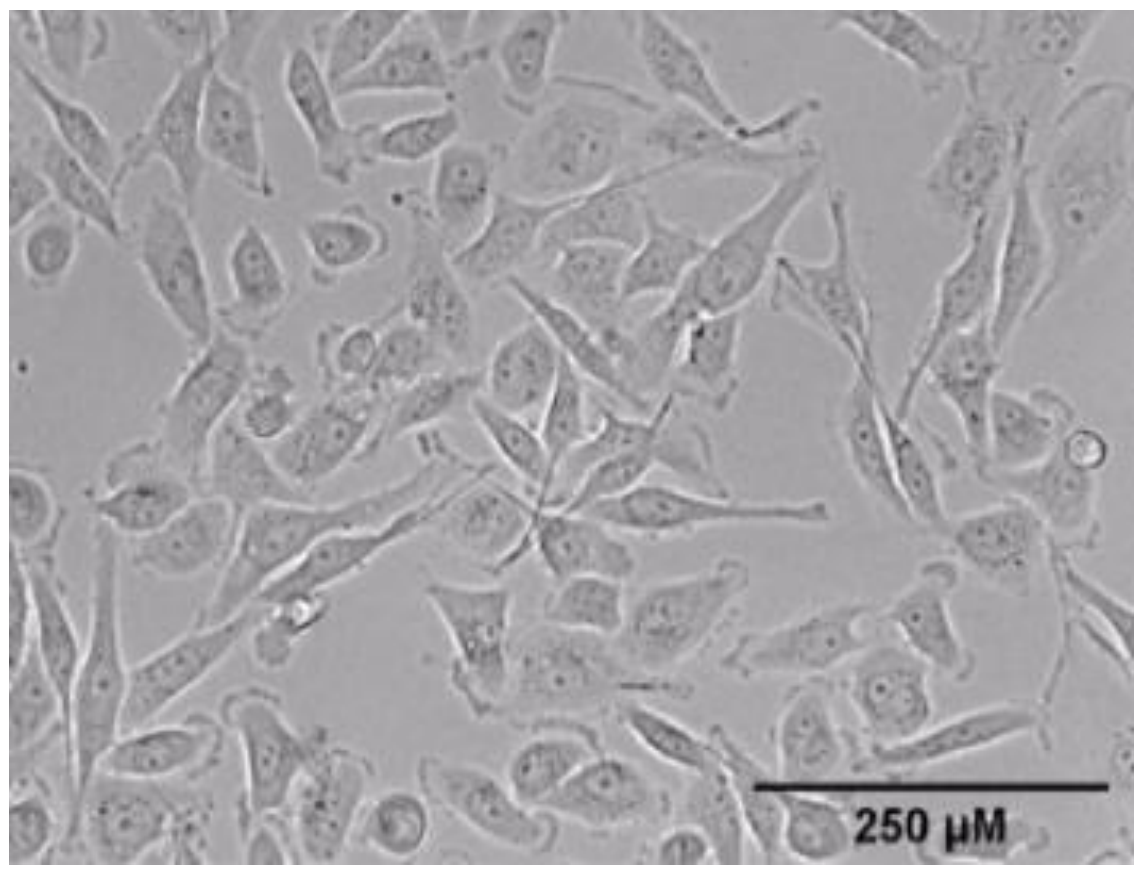

Figure 6. MDA-MB-231 TNBC cell line; 20X, Microscope: Lionheart Fx.

MDA-MB-231 cells were cultured at density of $1 \times 10^{5}$ cells $/ \mathrm{ml}$ in Dulbecco's Modified Eagle Medium (DMEM) (Gibco Thermo Fisher Scientific, USA) containing 10\% fetal bovine serum (FBS) (Gibco Thermo Fisher Scientific, USA), 1\% Penicillin-Streptomycin (10,000 U/ml) (Gibco 
Thermo Fisher Scientific, USA). The cells were maintained in a $37^{\circ} \mathrm{C}$ incubator with humidified $5 \% \mathrm{CO}_{2}$. Cells were subcultured to a new flask with fresh medium every third day, once they reached $\sim 90 \%$ confluence. For this, Trypsin-EDTA $0.05 \mathrm{mg} / \mathrm{ml}$ (Gibco Thermo Fisher Scientific, USA) was used and cells were incubated for 5 minutes at $37^{\circ} \mathrm{C}$. The cells were washed with phosphate buffer followed by centrifugation at $1200 \mathrm{rpm}$ for 5 minutes. Finally, the cells were resuspended in fresh DMEM medium (complemented with 10\% FBS and 1\% PenicillinStreptomycin).

\subsection{Cell culture devices}

\subsubsection{Falcon 96-well Clear Flat Bottom TC-treated Culture Microplate}

The Falcon 96-well Clear Microplate (Figure 7.) (Corning, USA) is comprised of clear tissue culture (TC)-treated polystyrene that enables cell attachment. The plate has flat bottomed wells, a working volume of 100-200 $\mu \mathrm{L}$, and is suitable for analysis of cells that grow in a monolayer. The low evaporation design of the lid allows optimal gas exchange while minimizing the risk of containation and evaporation (69).

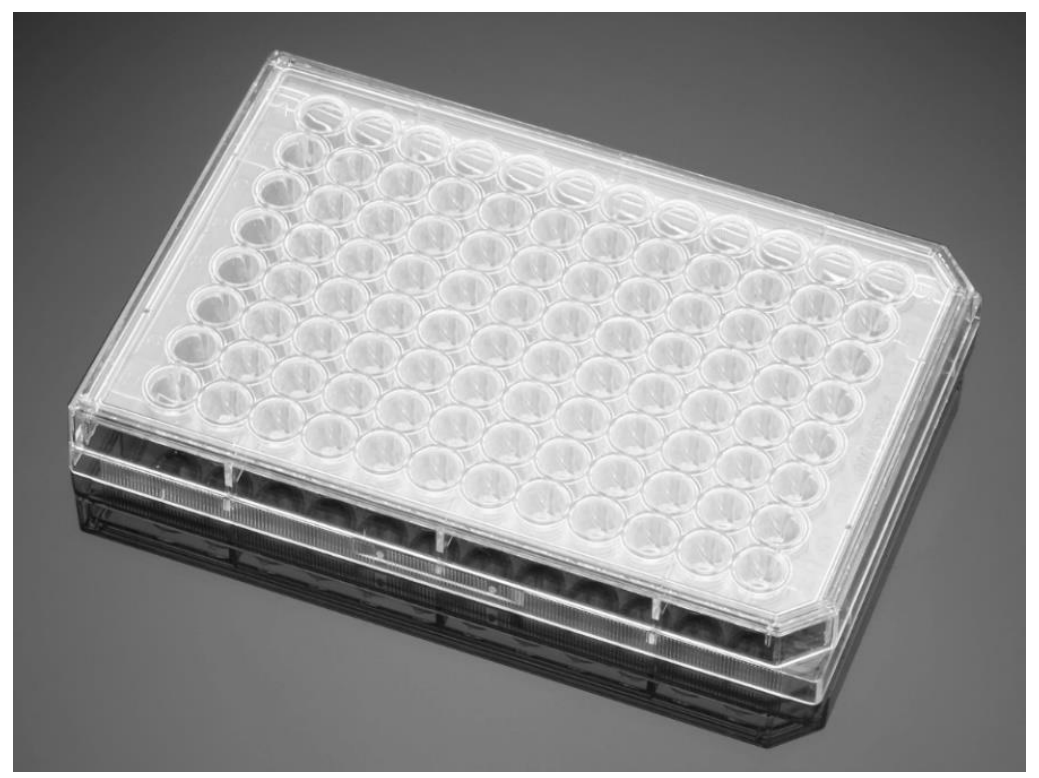

Figure 7. Design of Falcon 96-well Clear Flat Bottom TC-treated Culture Microplate. (69) 


\subsubsection{IBIDI $\mu$-Slide $4 \mathrm{Well} \mathrm{Ph}+$ ibiTreat}

An open $\mu$-Slide 4 Well Ph+ Chip (Ibidi, Germany) with 4 wells and special intermediate plate is optimized for phase contrast and fluorescence microscopy. The phase plate diminishes or removes the disturbance from the meniscus, so that the entire well can be examined (Figure 8). Openings near the corners provide access to the wells for easy filling and aspiration of liquids. Each of the 4 wells has a volume of $700 \mu \mathrm{L}$. This chip is made of a polymer of the highest optical quality and an optimal thickness of $170 \mu \mathrm{m}$, making it compatible with even high-resolution microscope objectives. The polymer coverslip on the bottom exhibits extremely low birefringence and autofluorescence, similar to that of glass. The ibiTreat surface is a physical surface modification that is optimized for adhesion of most cell types and is suitable for perfusion strategies analaysis (70).
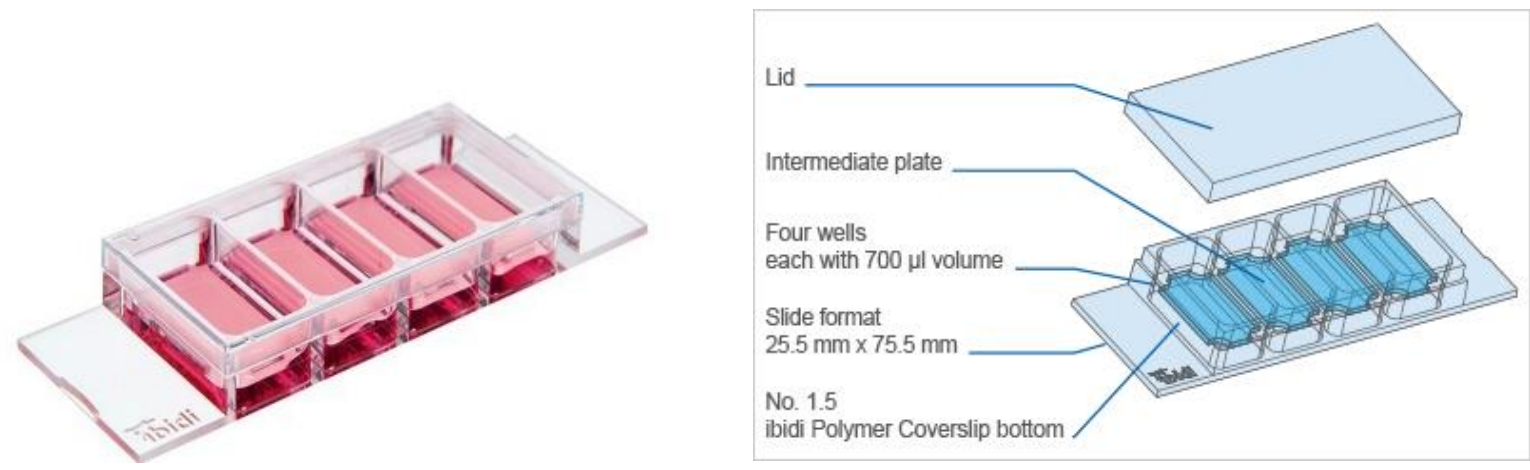

Figure 8. Design of an Ibidi $\mu$-Slide 4 Well Ph+ Chip. (70)

\subsection{Microscopes}

\subsubsection{Incucyte ${ }^{\circledR} \mathrm{S} 3$}

The Incucyte® S3 Live-Cell Analysis System (Figure 9.) is real-time quantitative system for livecell imaging. This system quantifies and visualizes different cellular processes, such as cell health and viability, migration, invasion, apoptosis and many other cellular changes over days and weeks in standard incubator. Images are automatically collected and analyzed which provides time-lapse, kinetic evaluation of dynamic cellular processes in living cells. In this way cells can be analyzed 
for days or even weeks since they are provided with stable environmental conditions inside the incubator. The system offers the possibility of accommodating up to six different plates in the incubator at the same time, with the possibility to determine specific schedule and imaging parameters (image acquisition, magnification) in parallel, with phase, red and green fluorescence modes.

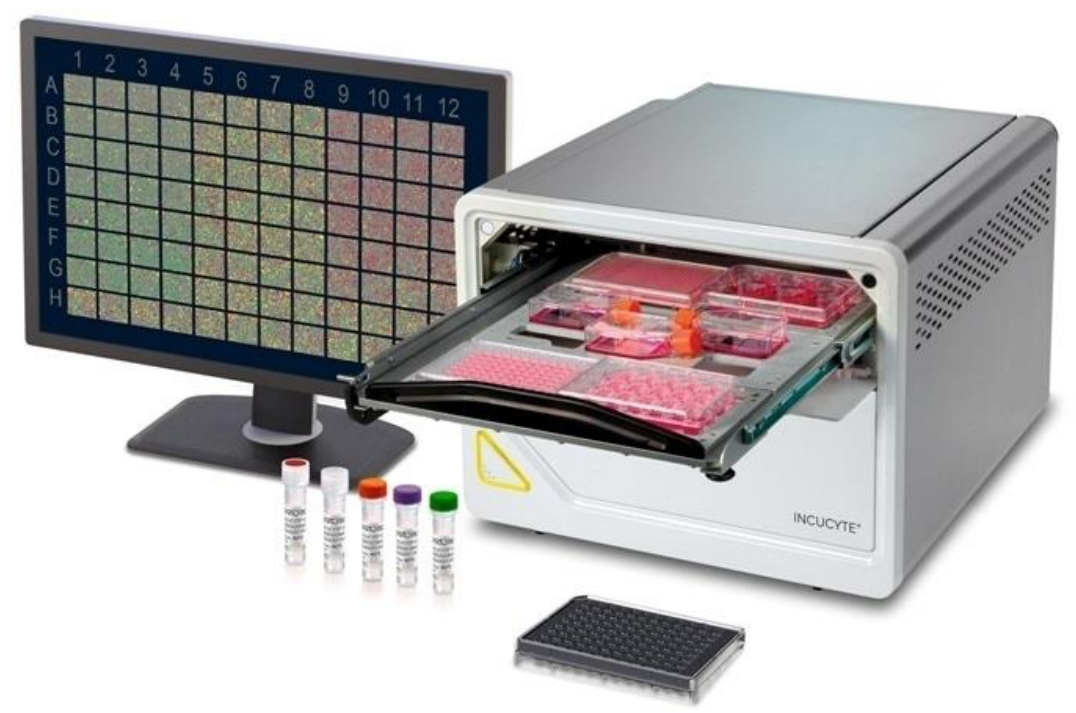

Figure 9. Incucyte® S3 Live-Cell Analysis System. (70)

In the experiments performed here, images were taken every 60 minutes for 48 hours using the 20X objective.

\subsection{Cell death analysis}

\subsubsection{Cell death evaluation with PI}

For cell death evaluation propidium iodide - PI (Sigma-Aldrich, Germany) was used. PI is a redfluorescent intercalating agent used for staining cells and nucleic acids. Since it is not permeant to live cells, it used to detect dead cells within a population. It binds to DNA by intercalating between the bases with little or no sequence preference (Figure 10). MDA-MB-231 cells were loaded into 96-well Microplate or into IBIDI $\mu$-Slide $4 \mathrm{Well} \mathrm{Ph}+$ through one of the openings on the intermediate plate under steril conditions. Either $100 \mu \mathrm{L}$ (96-well Microplate) or $700 \mu \mathrm{L}$ (4-well 
$\mu$-Slide) of cell suspension was seeded at a concentration of $1 \times 10^{5} / \mathrm{ml}$ in each well and left onvernight (24 hours) in the incubator at $37^{\circ} \mathrm{C}$ for the cells to attach. After incubation all wells were washed with sterile phosphate buffered saline (PBS) and then treated with desired drug combinations dissolved in Fluorobrite DMEM media (media without phenol red to reduce he background) containing PI $(0,25 \mu \mathrm{g} / \mathrm{ml})$. Cells were incubated for 30 minutes at $37{ }^{\circ} \mathrm{C}$ prior to imaging and placed in the Incucyte ${ }^{\circledR}$ S3 Live-Cell Analysis System. Four images were taken per well, every hour, for 48 hours using 20X magnification, phase and red objectives. PI evaluation was done by assessing the area of red fluorescent cells compared to all cells per well, detected as avarage phase contrast area. The avarage of the difference between all four positions describes each well for both, phase contrast and red fluorescent images.

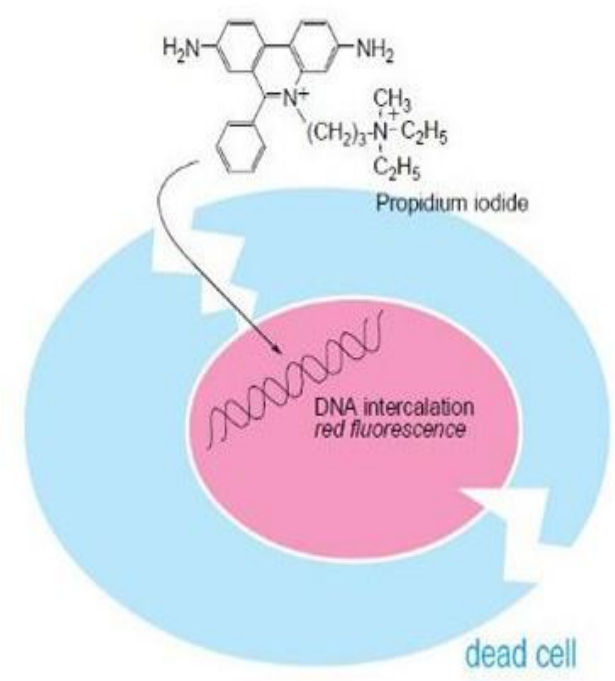

Figure 10. Propidium iodide (PI) intercalation in DNA of the dead cell. (71)

\subsubsection{Chloroquine/Hydroxychloroquine and chemotherapy combination therapy evaluation in 96 well plate}

MDA-MB-231 cells were loaded into a 96-well Microplate as described previously. After incubation all wells were washed with sterile phosphate buffered saline (PBS) and experiment was designed as follows: no treatment (control), $30 \mu \mathrm{M}$ Chloroquine (Sigma-Aldrich, Germany), 30 $\mu \mathrm{M}$ Hydroxychloroquine (Sigma-Aldrich, Germany), pretreatment with $30 \mu \mathrm{M}$ Chloroquine followed by chemotherapy drug (Gemcitabine, Camptothecin - Sigma-Aldrich, Germany), 
pretreatment with $30 \mu \mathrm{M}$ Hydroxychloroquine followed by chemotherapy drug (Gemcitabine, Camptothecin) and chemotherapy drug (Gemcitabine, Camptothecin) alone. After 6 hours incubation at $37^{\circ} \mathrm{C}$, the wells were washed with PBS and the wells pretreated with Chloroquine or Hydroxychloroquine were treated with different concentrations of the chosen chemotherapy drugs (Gemcitabine, Camptothecin) dissolved in Fluorobrite DMEM media (media without phenol red to reduce the background) containing PI $(0,25 \mu \mathrm{g} / \mathrm{ml})$ or left untreated (control). Cells were incubated for 30 minutes at $37^{\circ} \mathrm{C}$ prior to imaging and placed in the Incucyte® S3 Live-Cell Analysis System. Images were taken every 1 hour for 48 hours using $20 \mathrm{X}$ phase and red objective and 4 images per well were obtained. Dead cell evaluation is done by assessing the area of red fluorescent cells (PI-red fluorescence) compared to the area covered by all cells per well. All experiments were performed in triplicates.

\subsubsection{Chloroquine/Hydroxychloroquine and chemotherapy combination therapy evaluation in 4-well $\mu$-Slide}

In order to continue with work that has been done before by our collegue (72) where IBIDI $\mu$-Slide 4 well $\mathrm{Ph}+$ ibiTreat was used in order to follow the breast cancer cell growth in a developed liveimaging fluidic system we decided to use the same chip for evaluation of different treatment strategies in TNBC MDA-MB-231 cell line. Cells were loaded onto a IBIDI $\mu$-Slide 4 Well Ph+ as described previously. After incubation all wells were washed with sterile phosphate buffered saline (PBS) and the experiment was designed as follows: no treatment (control), pretreatment with $30 \mu \mathrm{M}$ Chloroquine followed by chemotherapy drug (Gemcitabine), pretreatment with 30 $\mu \mathrm{M}$ Hydroxychloroquine followed by chemotherapy drug (Gemcitabine) and chemotherapy drug (Gemcitabine) alone. After 6 hours of incubation at $37^{\circ} \mathrm{C}$, the wells were washed with PBS and the wells pretreated with Chloroquine or Hydroxychloroquine were treated with different concentrations of choosen chemotherapy drugs (Gemcitabine) dissolved in Fluorobrite DMEM media (media without phenol red to reduce the background) ontaining PI $(0,25 \mu \mathrm{g} / \mathrm{ml})$ or left un treated (control). Cells were incubated for 30 minutes at $37{ }^{\circ} \mathrm{C}$ prior to imaging and placed in an Incucyte $®$ S3 Live-Cell Analysis System. Images were taken every 1 hour for 48 hours using phase contrast and red fluorescence with the 20x objective and four images per well were obtained. 
Dead cell evaluation was done by assessing the area of red fluorescent cells (PI-red fluorescence) compared to the total area covered by cells per well.

\subsection{Image analysis}

Images were obtained using the Incucyte ${ }^{\circledR}$ S3 Live-Cell Analysis System and analyzed using the Incucyte ${ }^{\circledR}$ Analysis Software which contains purpose-built tools for image processing and analysis. First, analysis definition from images collected from each performed experiment is created which is then applied to every obtained image which needs to be analyzed. In order to evaluate cell death, the area covered by dead cells (PI-red fluorescence) is used as an indicator, where images were analyzed from the first until last the hour of the experiment, thus following the changes of area covered by dead cells over time. Four images were taken for each well and the average of the difference between all four positions describes each well for both, phase contrast and red fluorescent images.

\subsection{Statistical analysis}

To assess the statistical differecne between various treatment strategies and control SigmaPlot 14.0 (Systat Software, San Jose, CA, USA) software for Windows was used. The one-way ANOVA was performed, followed by Tukey test for multiple comparison. The difference between each group was considered statisticallz significant for p-value of 0.05 or less. 


\section{Results}

Chloroquine and its analogues have gained significant interest in cancer treatment where they have been incorporated in chemotherapeutic regimens and several clinical trials combining these drugs, in combination with chemotherapy. Many therapeutic approaches for highly aggressive and metastatic cancers, including breast cancer, involve the use of chloroquine, hydroxychloroquine and other chloroquine analogues application together with chemotherapy or radiotherapy due to their potential sensitizing role $(73,74)$. Because of the importance of finding new effective approaches in breast cancer treatment, we investigated the effectiveness of chloroquine and hydroxychloroquine on sensitizing the TNBC cell line to different chemotherapy drugs.

\subsection{Effects of chloroquine, hydroxychloroquine, gemcitabine and camptothecin as single agents and in combination at higher concentrations}

Cell death was determined after treatment with $30 \mu \mathrm{M}$ chloroquine, $30 \mu \mathrm{M}$ hydroxychloroquine, $10 \mu \mathrm{M}$ gemcitabine, $2 \mu \mathrm{M}$ camptothecin and pretreatment with either $30 \mu \mathrm{M}$ chloroquine or hydroxychloroquine for 6 hours after which $10 \mu \mathrm{M}$ gemcitabine or $2 \mu \mathrm{M}$ camptothecin was administrated. After treatment with these different drugs, cells were incubated for half an hour prior to 48-hour live cell imaging. Different biological proccesses can be observed within this system, from cell division to cell death. Figure 11. shows time-lapse imaging sequences where the initial (0. hour) and final (48. hour) state of cells after no treatment, as well as after treatment with $30 \mu \mathrm{M}$ chloroquine or hydroxychloroquine. Images obtained after $10 \mu \mathrm{M}$ gemcitabine, and its combination with $30 \mu \mathrm{M}$ chloroquine or hydroxychloroquine are depicted in Figure 12. As expected, non-treated cells are growing and dividing, which can be seen by the higher percentage of area occupied by cells at the end of the experiment. In contrary, when cells are treated with different drugs they are not dividing and cell death, such as due to apoptosis, can be observed. In the case of chloroquine and hydroxychloroquine given as single drugs not a lot of dead cells can be seen at the end of the experiment, though cells are not growing. In contrast, after treating cells with gemcitabine and its co-administration with chloroquine and hydroxychloroquine, cell death 
was increasing during the 48-hour experiment, which can be observed by increases in the red fluorescent intesity of the dead cell staining (Figure 12.) 


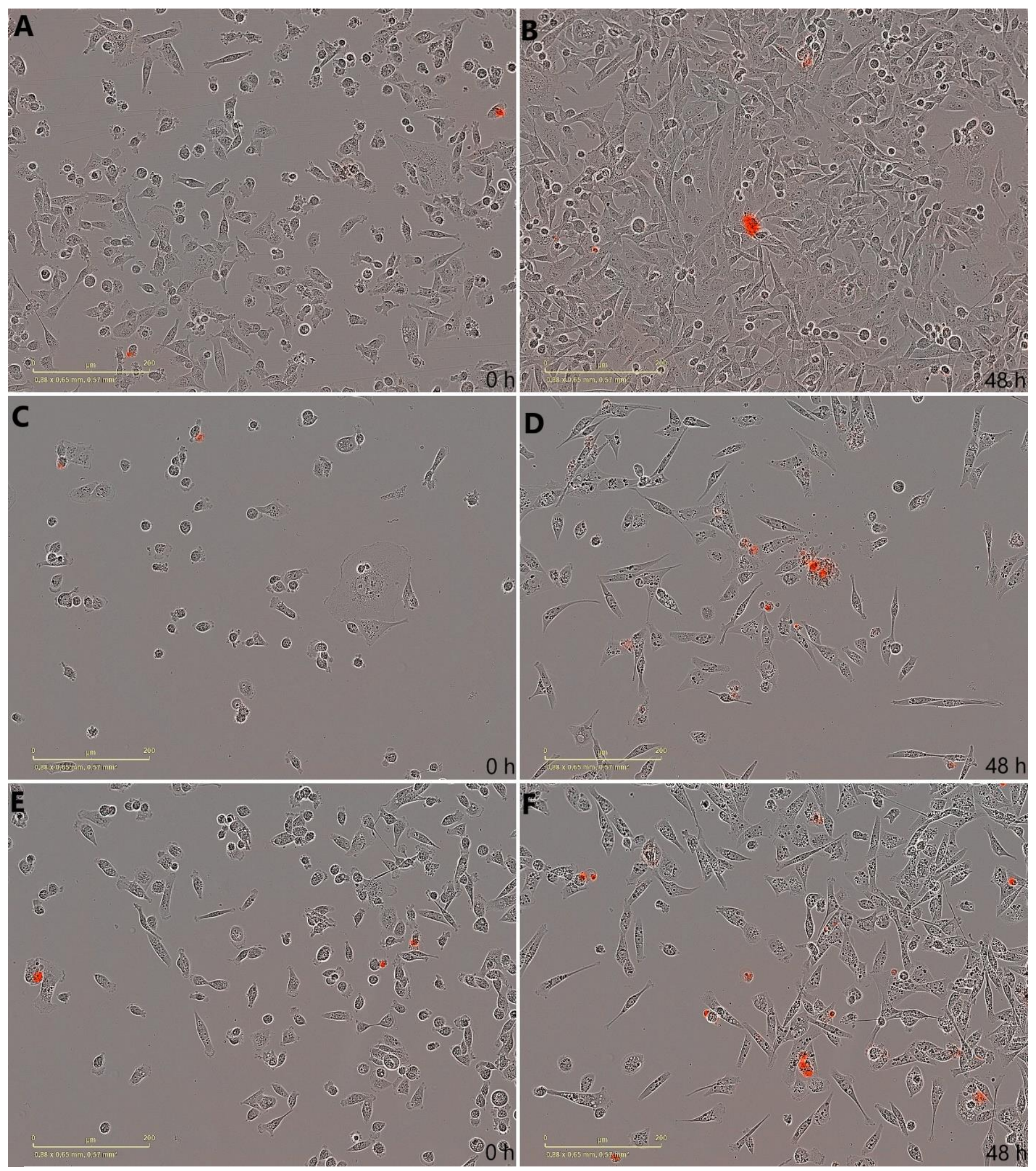

Figure 11. MDA-MB-231 cellular responses in 96-well plate. In this image sequence red dye (PI) is an indicator of dead cells. A) Control -O hour; B) Control-48 hours; C) $30 \mu M$ chloroquine - O hour; D) $30 \mu M$ chloroquine - 48 hours: E) $30 \mu M$ hydroxychloroquine - 0 hour; F) $30 \mu M$ hydroxychloroquine - 48 hours. 


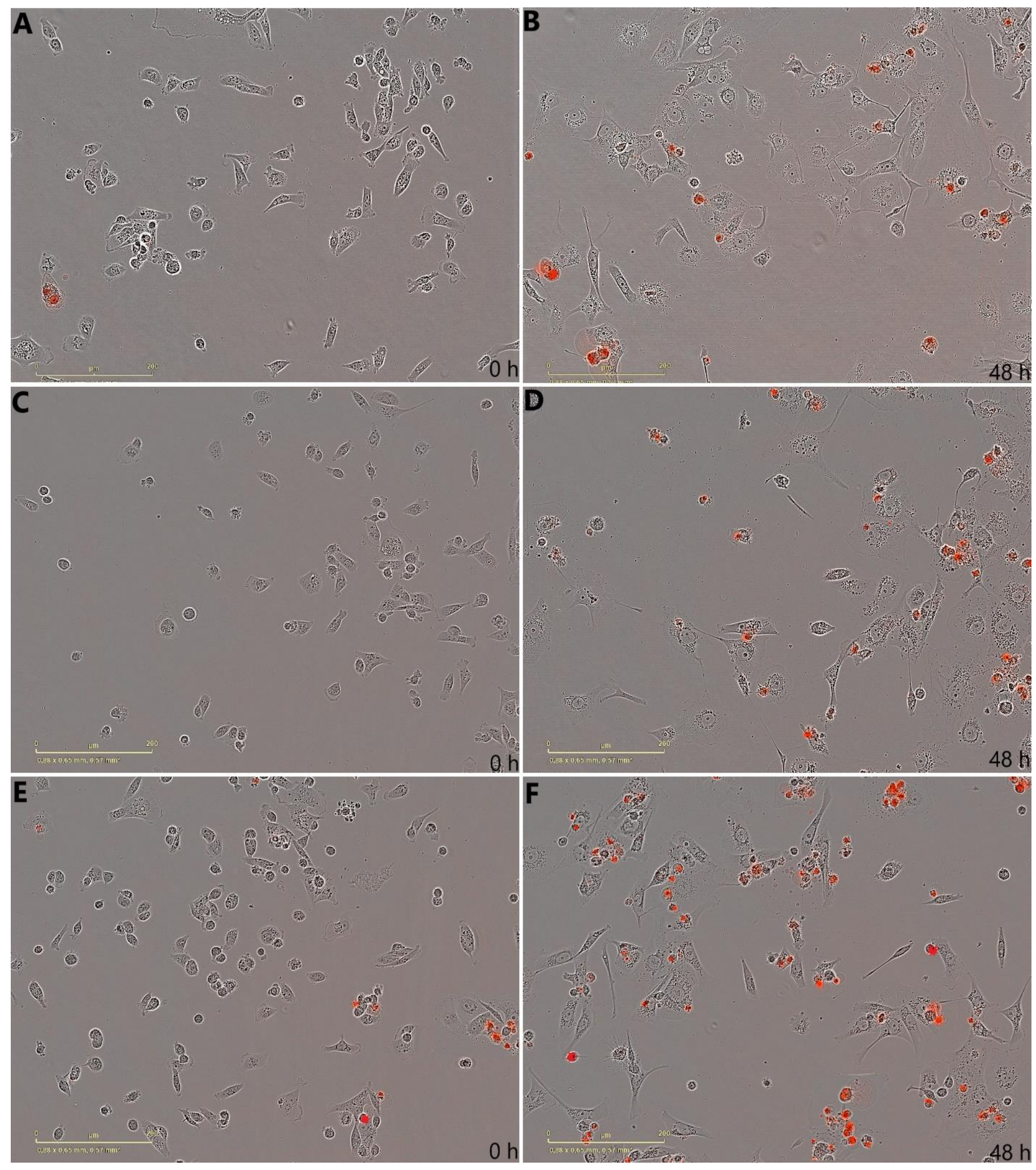

Figure 12. MDA-MB-231 cellular responses in 96-well plate after a different treatment strategy was applied. In this image sequence red dye (PI) is an indicator of dead cells. A) $10 \mu \mathrm{M}$ gemcitabine - 0 hour; B) $10 \mu \mathrm{M}$ gemcitabine - 48 hours; C) Pretreatment with $30 \mu M$ chloroquine $(6 h)+10 \mu M$ gemcitabine -0 hour; D) Pretreatment with $30 \mu M$ chloroquine $(6 h)+10 \mu \mathrm{M}$ gemcitabine -48 hours: E) Pretreatment with $30 \mu \mathrm{M}$ hydroxychloroquine $(6 h)+10 \mu \mathrm{M}$ gemcitabine; F) Pretreatment with $30 \mu M$ hydroxychloroquine $(6 h)+10 \mu M$ gemcitabine. 
A
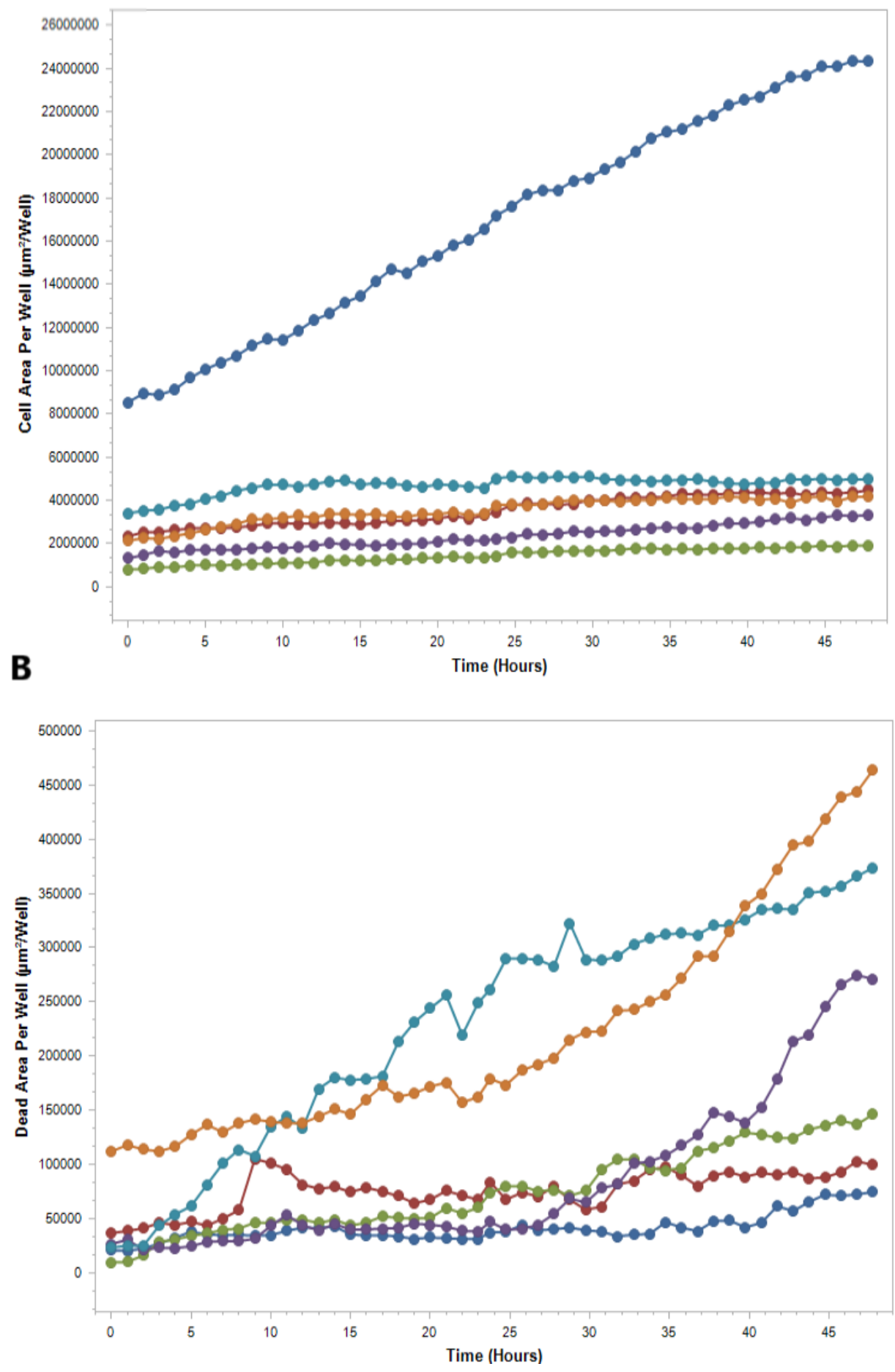

- Control-no treatment

$-30 \mu \mathrm{M} \mathrm{CQ}$

$-30 \mu \mathrm{M} \mathrm{HCQ}$

$-10 \mu \mathrm{M}$ Gemcitabine $C Q(30 \mu \mathrm{M})+$ $10 \mu \mathrm{M}$ Gemcitabine $\mathrm{HCQ}(30 \mu \mathrm{M})+$ $10 \mu \mathrm{M}$ Gemcitabine

Figure 13. Image analysis of TNBC MDA-MB-231 response to different treatment strategies followed for 48 hours. Cells were treated with $30 \mu M$ chloroquine, $30 \mu M$ hydroxychloroquine, $10 \mu M$ gemcitabine or pretreated with $30 \mu \mathrm{M}$ chloroquine or hydroxychloroquine for 6 hours after which $10 \mu \mathrm{M}$ gemcitabine is added. A. Cell population was assessed by analyzing cell area covered by cells over 48 hours. B. Dead area over 48 hours is determined by detecting red fluorescence per each well. 
The cell area per well (Figure 13A.) is related to the entire cell population of the sample, whereas the dead area (Figure 13B.) was measured by detection of the area covered by red fluorescence (PI). Images were taken every hour at four positions per well, whereas the average value of the four positions is used to decsribe each well.

We observed that the cell area in the untreated control samples increased constantly compared to all of the other conditions, in which different drugs were administrated. The differences were significant $(\mathrm{p}<0.05)$ between control and every treatment strategy. A significant difference $(\mathrm{p}<0.05)$ was also observed in the case of dead area covered by red fluorescence where dead area was significantly higher in sample pretreated with $30 \mu \mathrm{M}$ hydroxychloroquine followed by $10 \mu \mathrm{M}$ gemcitabine compared with drugs applied as single agents. Dead area in the case of $30 \mu \mathrm{M}$ hydroxychloroquine pretreatment is slightly increasing at the beginning of the experiment and after 25-hours it is in constant increase, with the highest amount of dead cells present after 48 hours compared to all other conditions in the experiment. When cells are pretreated with $30 \mu \mathrm{M}$ chloroquine the area covered by dead cells followed a similar pattern as in the case of $30 \mu \mathrm{M}$ hydroxychloroquine pretreatment, with no significant difference $(p=0.993)$ between these two treatment approaches. In this case, bigger increases in dead cell area can be observed in first 24 hours (4-fold more dead cell area after the first 10 hours) after which cells continued to die but in slower manner, with significant difference $(\mathrm{p}<0.05)$ observed between chloroquine pretreatment followed by gemcitabine and all three conditions when the drugs were applied as single agents.

Camptothecin, human DNA topoisomerase I inhibitor, was also used in this experiment. As previously described, cells were treated with $30 \mu \mathrm{M}$ chloroquine and $30 \mu \mathrm{M}$ hydroxychloroquine as a single agent as well as $2 \mu \mathrm{M}$ camptothecin and pretreated with $30 \mu \mathrm{M}$ chloroquine and $30 \mu \mathrm{M}$ hydroxychloroquine for 6 hours. After pretreatment, $2 \mu \mathrm{M}$ camptothecin was added and the cells were incubated for 30 minutes before the start of imaging. Images of MDA-MB-231 TNBC obtained during these treatment strategies are shown in Figure 14. Similarly to the gemcitabine response, after image analysis was performed it can be observed that cell area during 48 hours is not increasing in the case of treatment with the different drugs, both as single agents and in the combinations as administrated in respect to control samples, with significantly $(\mathrm{p}<0.05)$ lower area occupied by cells. Red fluorescent detection increased constantly when cells were pretrated with $30 \mu \mathrm{M}$ chloroquine and $30 \mu \mathrm{M}$ hydroxychloroquine, where, in case of hydroxychloroquine pretreatment, few dead cells were detected within the first hour of live-cell imaging (Figure 15.), 
whereas when the same concentration of chloroquine was administrated prior to camptothecin administration, the dead area covered by cells started to grow with every hour. After 24 hours cell death increases, reaching a slightly higher amount of area covered by dead cells with respect to Hhydroxychloroquine pretreatment (Figure 15.). Additionally, no statitstically significant difference was found between these two treatment approaches $(\mathrm{p}=0,053)$, but the difference was significant $(\mathrm{p}<0,05)$ between single drug treatments and hydroxychloroquine pretreated cells, as well as between all five conditions when drugs were applied compared to the control. In the case of chloroquine pretreatment, statistically significant differences were not observed $(p=0,146)$ when this treatment strategy was compared with camptothecin alone, which means that hydroxychloroquine pretreatment was more efficient in sensitizing cells to camptothecin during a 48-hour observation. Moreover, the difference between the camptothecin and chloroquine combination, the camptothecin and hydroxychloroquine combination and chloroquine and hydroxychloroquine when administrated as single drugs were not statistically significant $(\mathrm{p}=0,995$; $\mathrm{p}=0,882 ; \mathrm{p}=0,993$ respectively). 


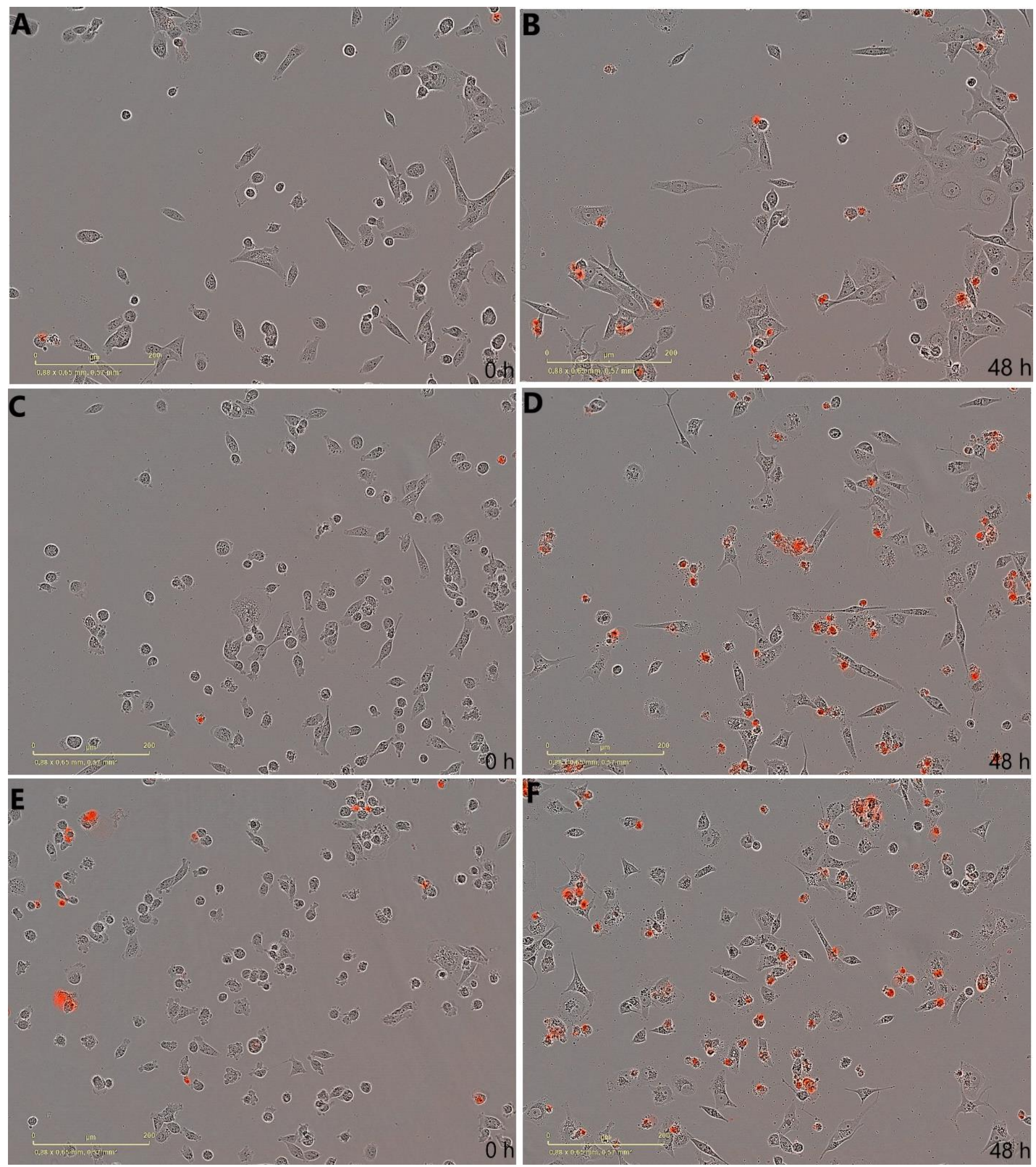

Figure 14. MDA-MB-231 cellular responses in 96-well plate after different treatment strategy were applied. In this image sequence red dye (PI) is an indicator of dead cells. A) $2 \mu M$ camptothecin-0 hour; B) $2 \mu M$ camptothecin-48 hours; $C)$ Pretreatment with $30 \mu M$ chloroquine $(6 h)+2 \mu M$ camptothecin -0 hour; D) Pretreatment with $30 \mu M$ chloroquine $(6 h)+2 \mu M$ camptothecin -48 hours: E) Pretreatment with $30 \mu M$ hydroxychloroquine $(6 h)+2 \mu M$ camptothecin; F) Pretreatment with $30 \mu M$ hydroxychloroquine $(6 h)+2 \mu M$ camptothecin. 


\section{A}

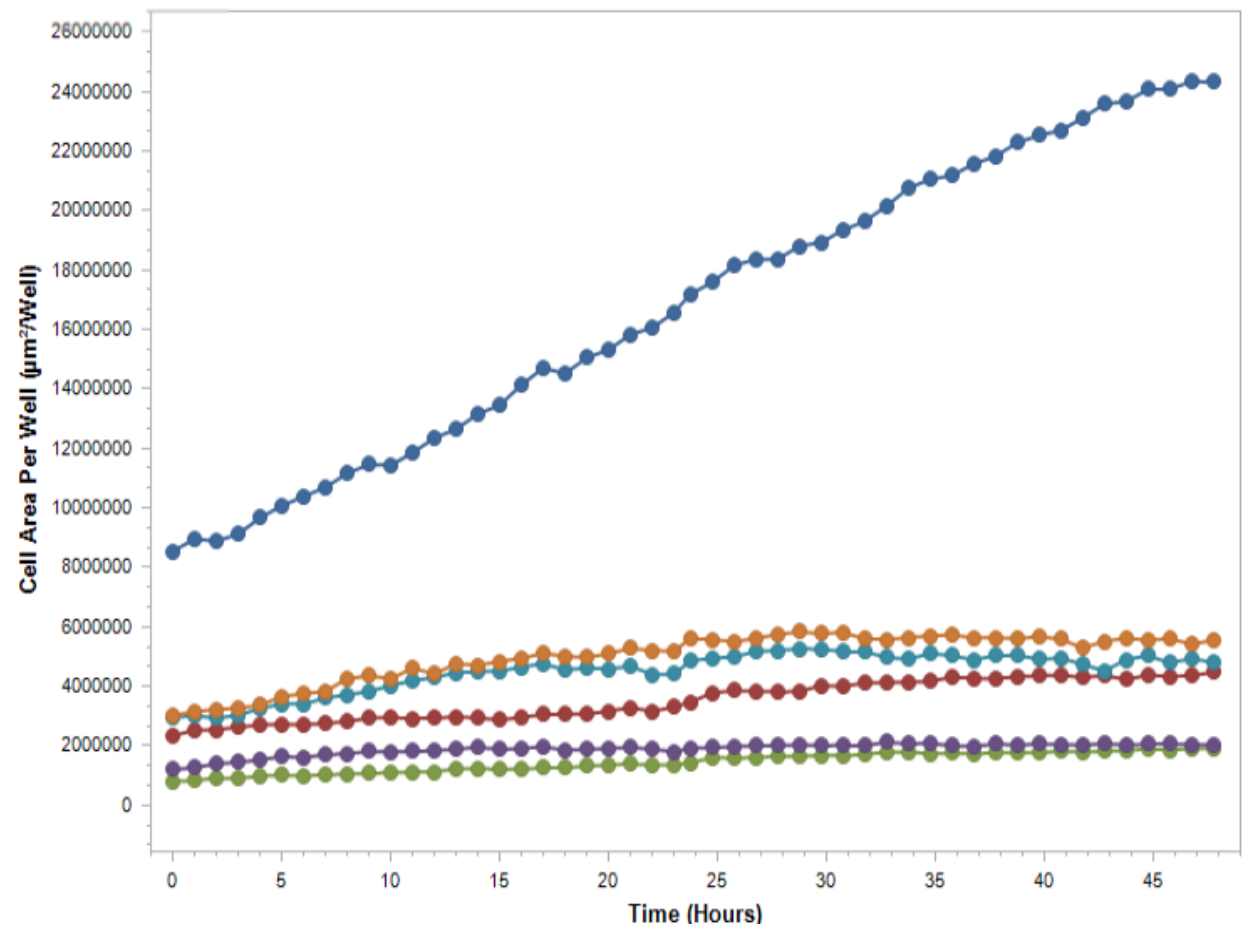

B

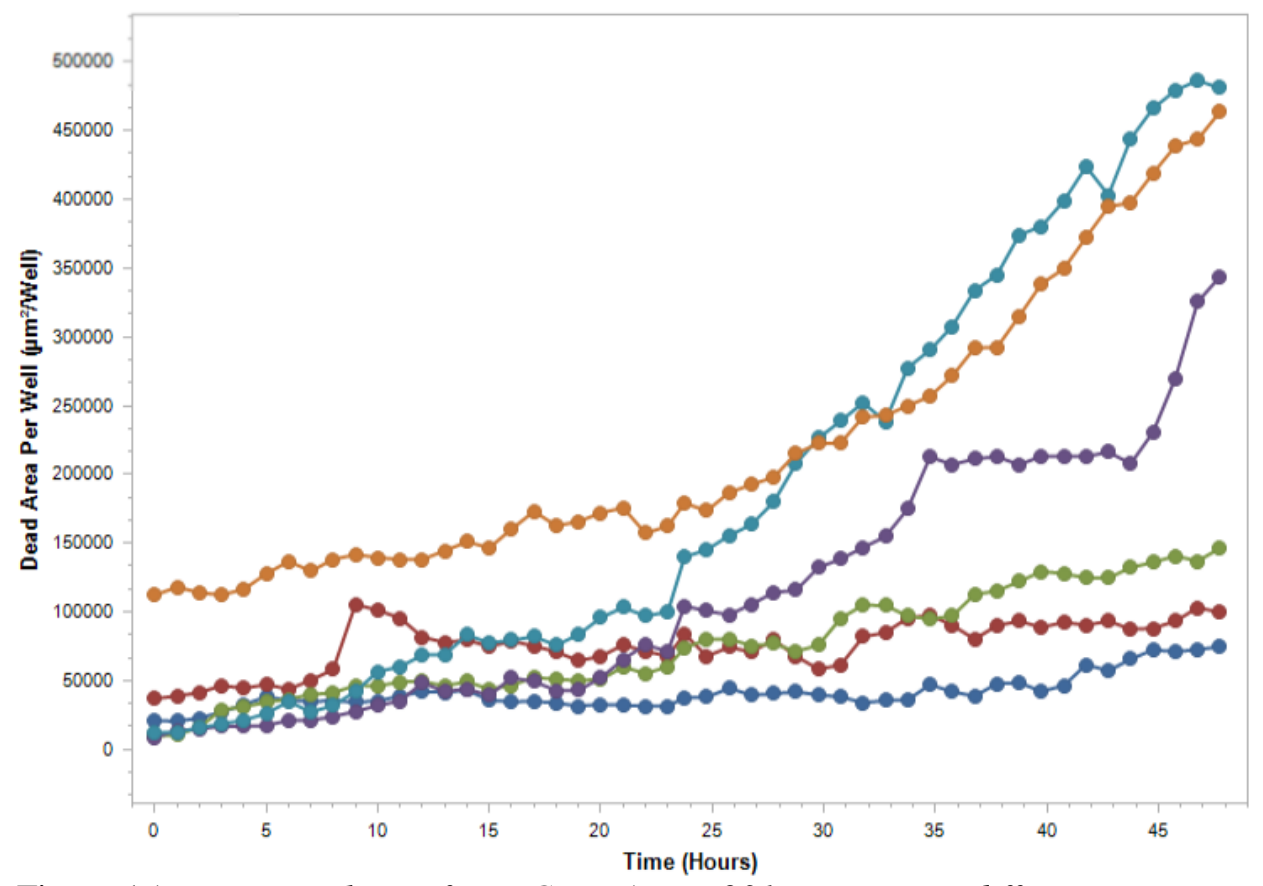

Figure 15. Image analysis of TNBC MDA-MB-231 response to different treatment strategies followed for 48 hours. Cells were treated with $30 \mu M$ Chloroquine, $30 \mu M$ Hydroxychloroquine, $2 \mu M$ Camptothecin or pretreated with $30 \mu M$ Chloroquine or Hydroxychloroquine for 6 hours after which $2 \mu M$ Camptothecin was added. A) Cell population was assessed by analyzing cell area covered by cells over 48 hours. B) Dead area over 48 hours is determined by detecting red fluorescence per each well. 
Since MDA-MB-231 TNBC response to $10 \mu \mathrm{M}$ gemcitabine and $2 \mu \mathrm{M}$ camptothecin showed significant increases in the dead cell areas during 48-hour live-cell imaging, lower concentrations of gemcitabine and camptothecin were applied in next experiment, combined with the same concentration of chloroquine and hydroxychloroquine as pretreatments.

\subsection{Effects of chloroquine, hydroxychloroquine, gemcitabine and camptothecin as single agents and in combination at lower concentrations}

As in the previous experiment, cells were treated with $30 \mu \mathrm{M}$ chloroquine, $30 \mu \mathrm{M}$ hydroxychloroquine, $0,5 \mu \mathrm{M}$ gemcitabine and $0,5 \mu \mathrm{M}$ camptothecin and their combination (pretreatment with $30 \mu \mathrm{M}$ chloroquine or $30 \mu \mathrm{M}$ hydroxychloroquine for 6 hours followed by 0,5 $\mu \mathrm{M}$ gemcitabine and $0,5 \mu \mathrm{M}$ camptothecin) with a 30 minute incubation period before imaging. Area covered by dead cells was analyzed, with red fluorescence serving as an indicator of dead cells. Cell response in the control samples (images not shown), followed similar patterns as in the previous experiment, where cells were actively dividing, thus occupying more area of the well throughout the 48-hour imaging period. Significant differences $(\mathrm{p}<0,05)$ were observed between the control and all of the drug treatments, either alone or in combinations. Similarly, when chloroquine and hydroxychloroquine were given as single agents, cells were neither dying nor dividing (images not shown), which shows that these drugs exert effects on cancer cells. Representative images from the beginning and the end of the experiment (Figure 16.) show that hydroxychloroquine enhanced the anticancer effect of gemcitabine at the lower concentration $(0,5$ $\mu \mathrm{M})$ with higher dead area at the end of the experiment compared to gemcitabine alone, but this difference was not statistically significant ( $\mathrm{p}=0.063)$. Cell death after 48 hours can also be observed when chloroquine was administrated as a pretreatment agent, but with less dead cell area at the end of the experiment, although a significant difference $(\mathrm{p}<0.05)$ was still observed between the two pretreatment strategies. From image analysis results (Figure 17.) it can be observed that both pretreatment strategies were significantly more efficient compared to gemcitabine given as a single agent, meaning that these drugs may have sensitizing effect on chemotherapy drugs, in this case gemcitabine, at $0,5 \mu \mathrm{M}$ concentration. This observaation is also supported by statistical analysis, where statistically significant differences $(\mathrm{p}<0,05)$ was found when chloroquine and hydroxychloroquine co-administration with gemcitabine was compared with gemcitabine 
treatment alone. Although cells with chloroquine pretreatment showed slightly greater dead cell area in the first hour of experiment, after 32 hours there was no increase in amount of dead cells by end of the experiment. In contrast, hydroxychloroquine administration followed by gemcitabine was constantly increasing. Similar to the previous experiment, after 24 hours, we can observe a significant increase in area covered by dead cells, when the cells were treated with higher $(10 \mu \mathrm{M})$ gemcitabine concetration. Gemcitabine given as a single agent, with $0,5 \mu \mathrm{M}$ concentration resulted in far less dead cell area during the 48-hour imaging period, as well as chloroquine and hydroxychloroquine alone, with no statistically significant difference between these three drugs ( $\mathrm{p}=0.655 ; \mathrm{p}=0.307$, respectively). 


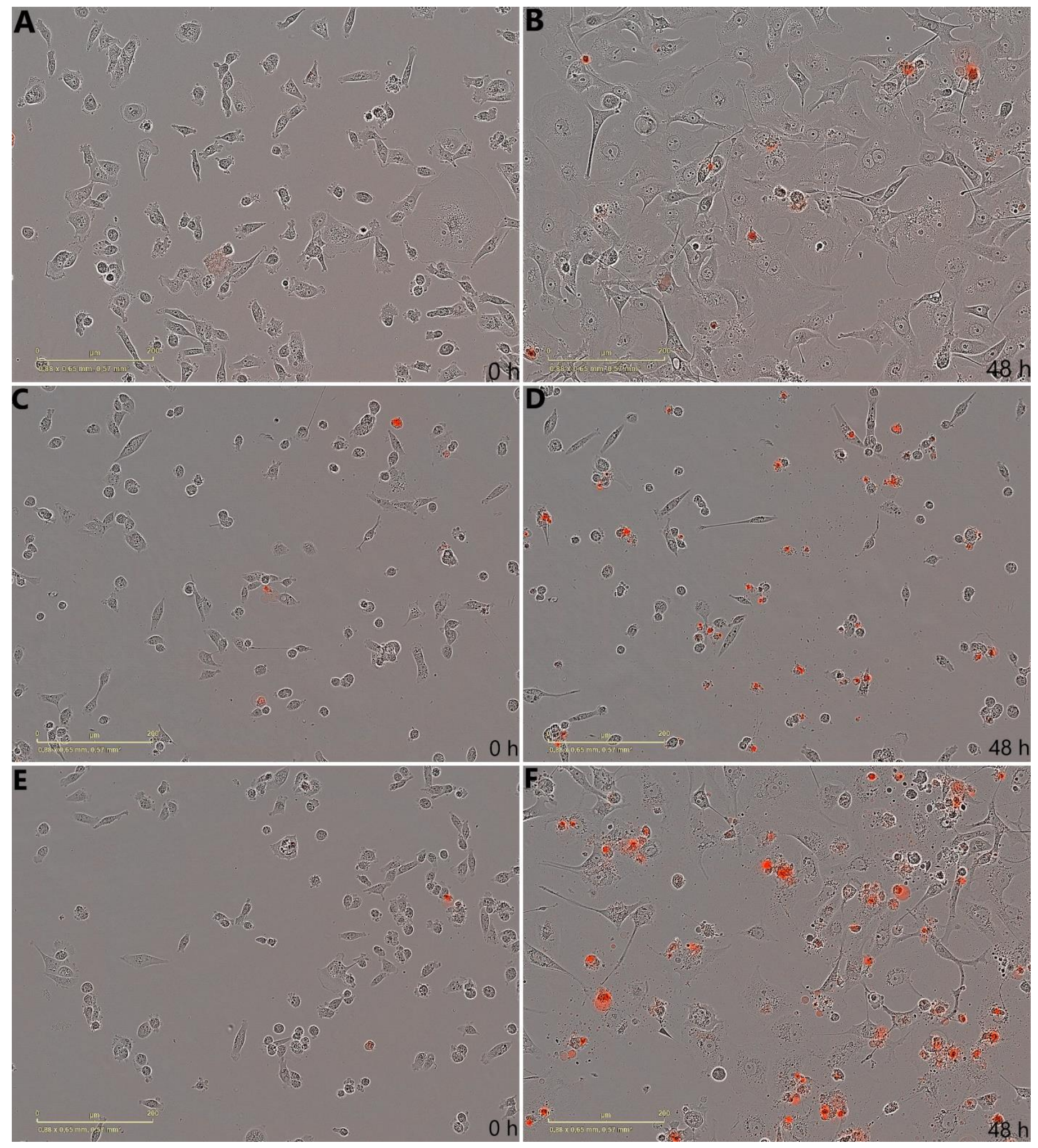

Figure 16. MDA-MB-231 cellular responses in a 96-well plate after different treatment strategy was applied. In this image sequence red dye (PI) is an indicator of dead cells. A) 0,5 $\mu \mathrm{M}$ gemcitabine - 0 hour; B) 0,5 $\mu \mathrm{M}$ gemcitabine - 48 hours; C) Pretreatment with $30 \mu \mathrm{M}$ chloroquine $(6 \mathrm{~h})+0,5 \mu \mathrm{M}$ gemcitabine - 0 hour; D) Pretreatment with $30 \mu \mathrm{M}$ chloroquine $(6 h)+0,5 \mu M$ gemcitabine -48 hours: E) Pretreatment with $30 \mu M$ hydroxychloroquine $(6 h)+0,5 \mu M$ gemcitabine; F) Pretreatment with $30 \mu M$ hydroxychloroquine $(6 h)+0,5 \mu M$ gemcitabine. 


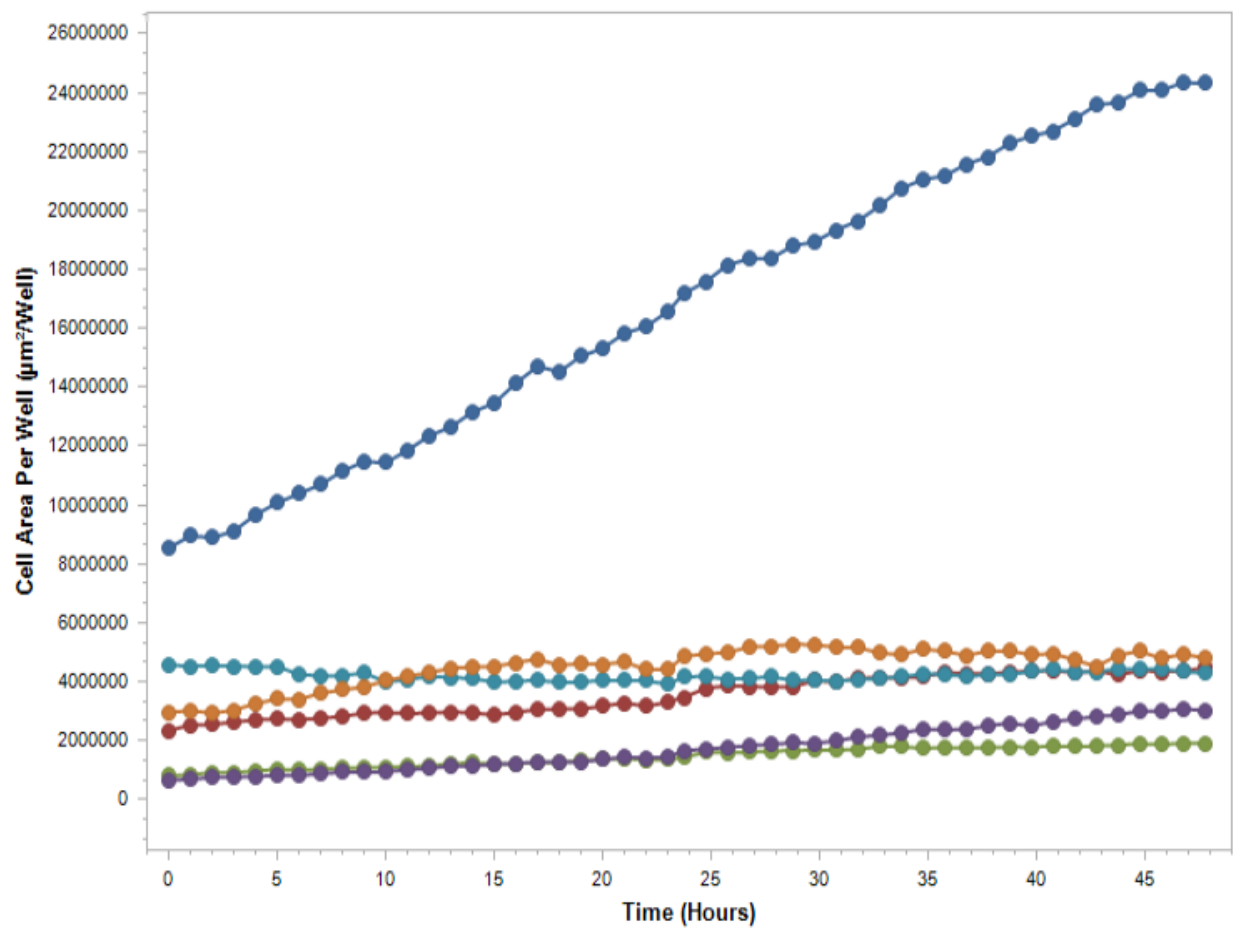

B

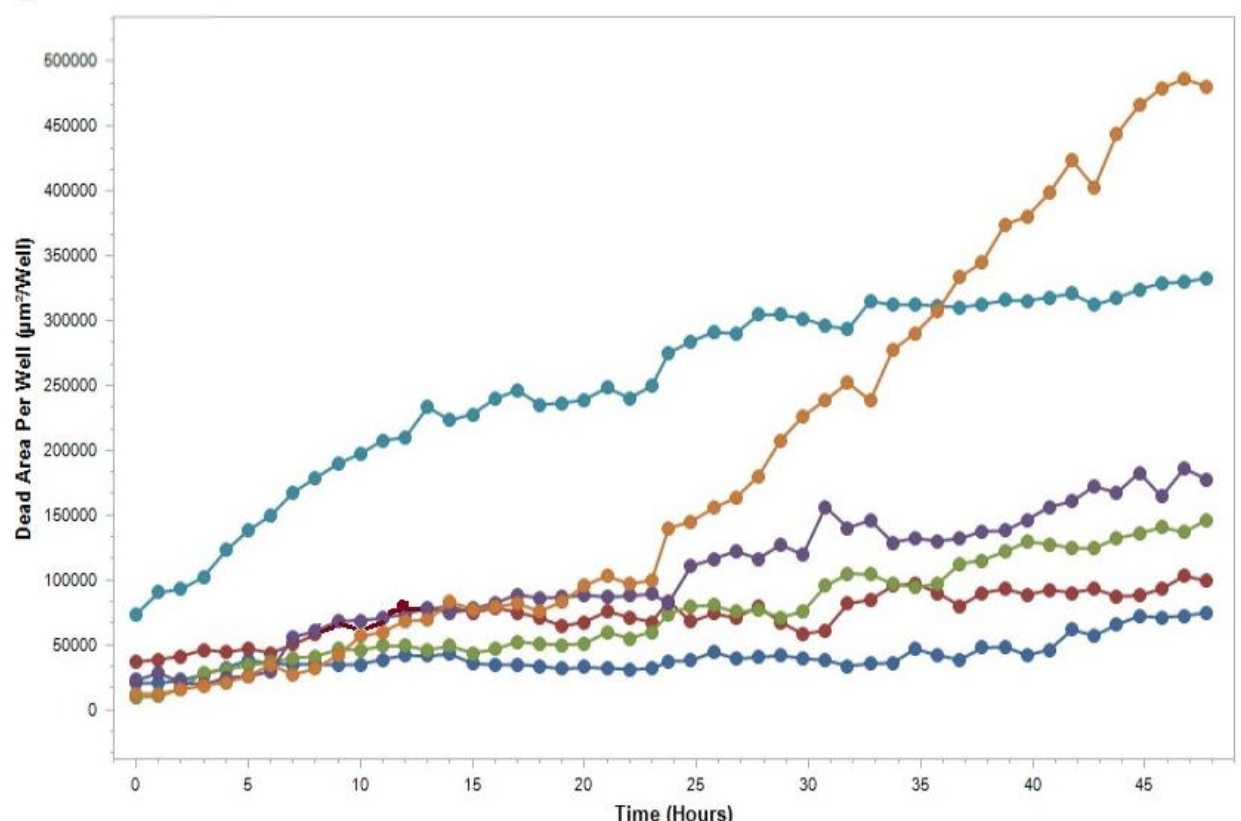

- Control - no treatment $-30 \mu \mathrm{M} \mathrm{CQ}$

$-30 \mu \mathrm{M} \mathrm{HCQ}$ $-0.5 \mu \mathrm{M}$ Gemcitabine $\mathrm{CQ}(30 \mu \mathrm{M})+$ $0.5 \mu \mathrm{M}$ Gemcitabine $\mathrm{HCQ}(30 \mu \mathrm{M})+$ $0.5 \mu \mathrm{M}$ Gemcitabine

Figure 17. Image analysis of TNBC MDA-MB-231 response to different treatment strategies followed for 48 hours. Cells were treated with $30 \mu M$ chloroquine, $30 \mu M$ hydroxychloroquine, 0,5 $\mu M$ gemcitabine or pretreated with $30 \mu \mathrm{M}$ chloroquine or hydroxychloroquine for 6 hours after which 0,5 $\mu \mathrm{M}$ gemcitabine is added A) Cell population was assessed by analyzing cell area covered by cells over 48 hours. B) Dead area over 48 hours is determined by detecting red fluorescence per each well. 
Another set of images obtained during MDA-MB-231 live-imaging when camptothecin at lower concentration $(0,5 \mu \mathrm{M})$ was administrated, alone or after chloroquine and hydroxychloroquine pretreatments (30 $\mu \mathrm{M}$ concentration) was analyzed. The biological response to these treatment strategies is presented in Figure 18. Again, cell response to hydroxychloroquine pretreatment followed by camptothecin resulted in the highest number of dead cells, which increased constantly during 48-hours of live cell imaging, a with five-fold increase within the first 22 hours (Figure 19.). Likewise, after chloroquine pretreatment the cells were not growing, but dying, where these dying cells occupied slightly less area compared to those from the hydroxychloroquine pretreatment. No statistically significant difference was observed between these two treatment strategies $(p=995)$. When cells were treated with chloroquine, hydroxychloroquine and camptothecin as single agents the red fluorescent detection was lower compared to combination of these drugs, although the area occupied by dead cells in case of $0,5 \mu \mathrm{M}$ camptothecin increased by three-fold at the end of the experiment. After applying a Tukey test for multiple comparison, statistically significant difference $(\mathrm{p}<0.05)$ between single drug treatments and chloroquine/hydroxychloroquine pretretament strategies followed by camptothecin was detected. The results with lower concentrations of gemcitabine and camptothecin co-administrated after chloroquine and hydroxychloroquine have led to the conclusion that these drugs enhance anticancer effects of chemotherapy drugs in the case of the MDA-MB-231 TNBC cell line, when we applied Gemcitabine and Camptothecin as our drugs of choice. 


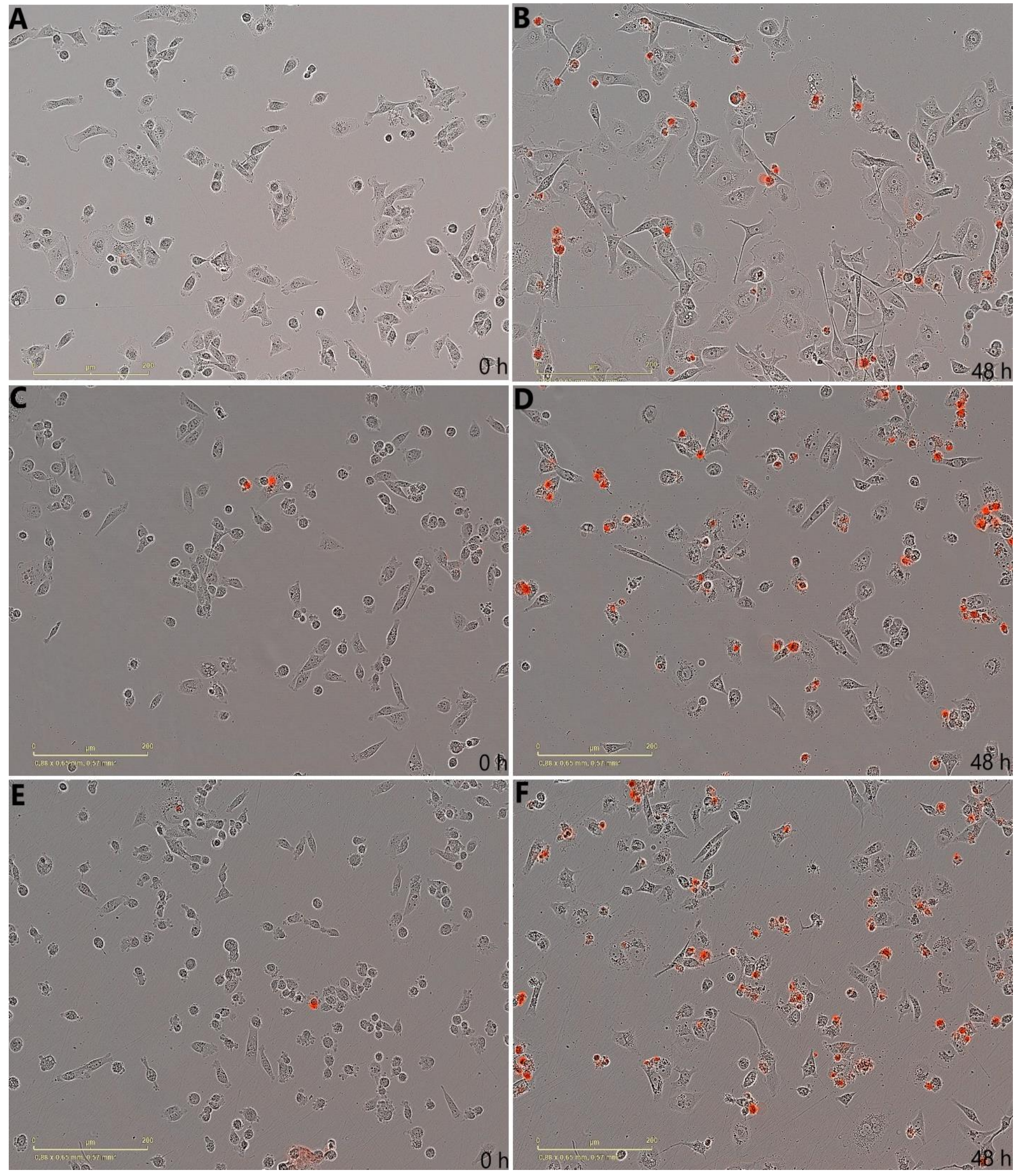

Figure 18. MDA-MB-231 cellular responses in a 96-well plate after different treatment strategy was applied. In this image sequence red dye (PI) is an indicator of dead cells. A) 0,5 $\mu M$ camptothecin-0 hour; B) 0,5 $\mu M$ camptothecin-48 hours; C) Pretreatment with $30 \mu \mathrm{M}$ chloroquine $(6 \mathrm{~h})+0,5 \mu \mathrm{M}$ camptothecin -0 hour; D) Pretreatment with $30 \mu \mathrm{M}$ chloroquine $(6 h)+0,5 \mu M$ camptothecin -48 hours: E) Pretreatment with $30 \mu M$ hydroxychloroquine $(6 h)+0,5 \mu M$ camptothecin; F) Pretreatment with $30 \mu M$ hydroxychloroquine $(6 h)+0,5 \mu M$ camptothecin. 


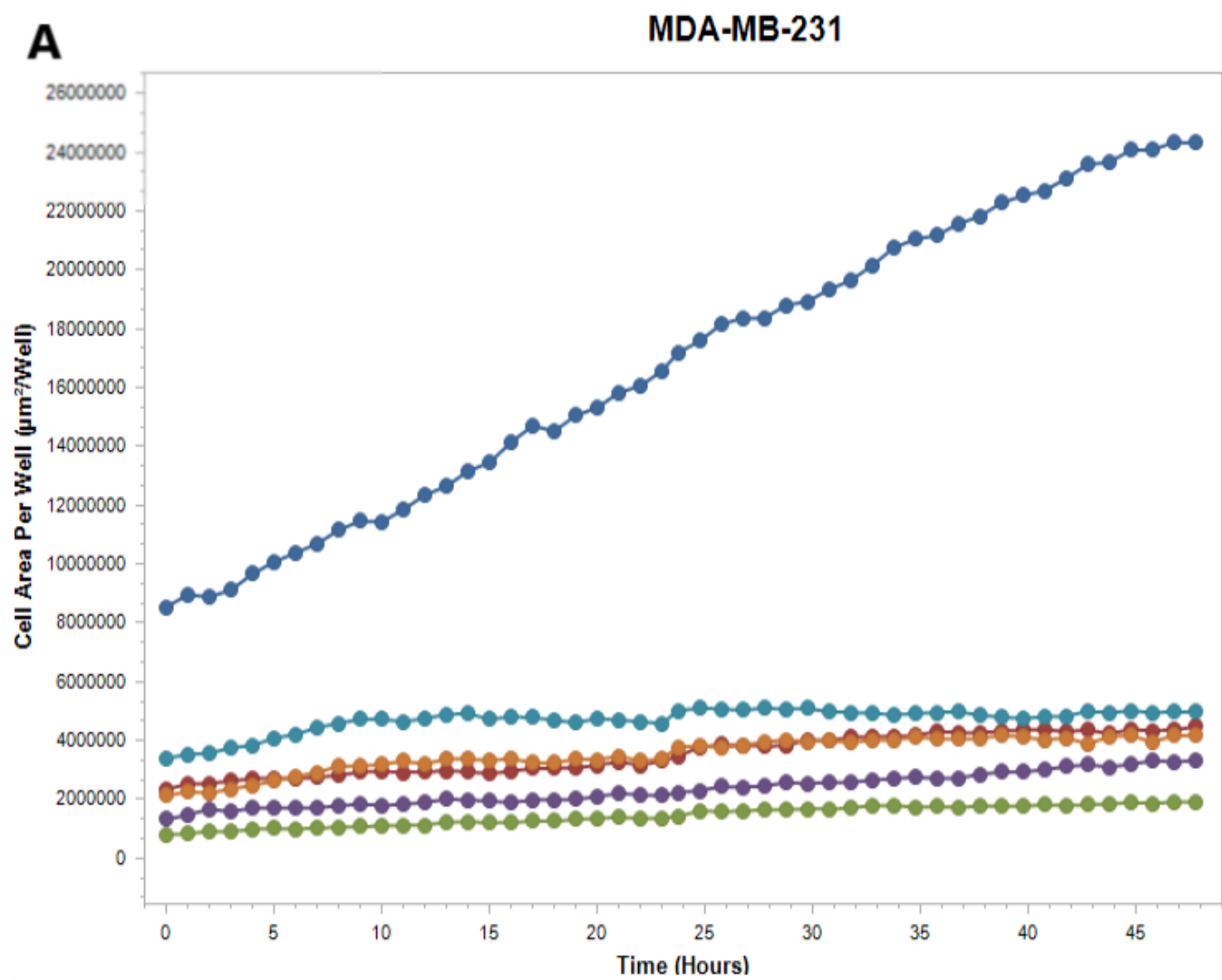

B

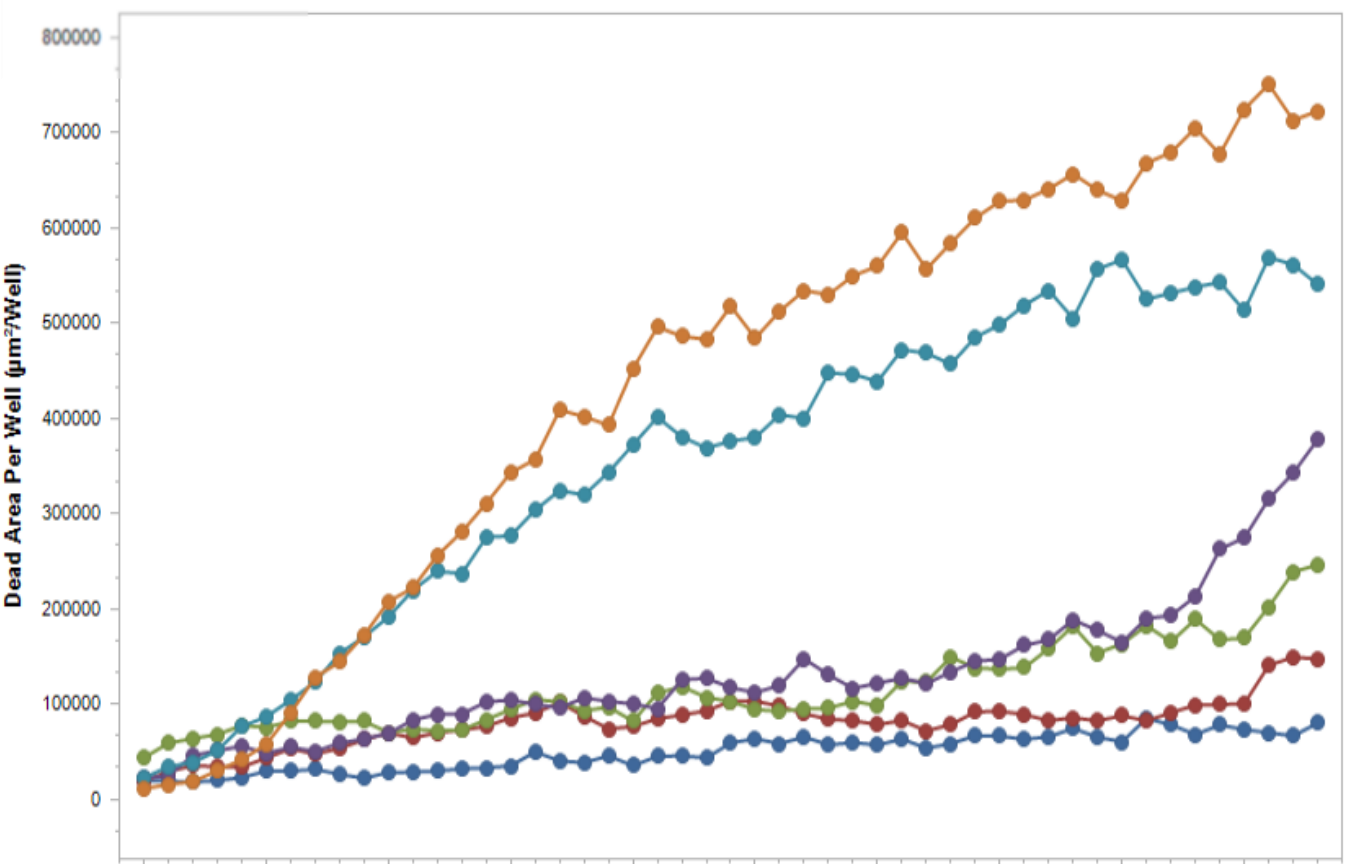

Figure 19. Image analysis of TNBC MDA-MB-231 response to different treatment strategies followed for 48 hours. Cells were treated with $30 \mu \mathrm{M}$ chloroquine, $30 \mu \mathrm{M}$ hydroxychloroquine, $0,5 \mu \mathrm{M}$ camptothecin or pretreated with 30 $\mu M$ chloroquine or hydroxychloroquine for 6 hours after which $0,5 \mu M$ camptothecin is added A) Cell population was assessed by analyzing cell area covered by cells over 48 hours. B) Dead area over 48 hours is determined by detecting red fluorescence per each well. 


\subsection{Effects of chloroquine, hydroxychloroquine and gemcitabine as single agents and in combination in 4-well chip}

Since the further goal of the chloroquine/hydroxychloroquine co-administration with chemotherapy drugs is to apply different perfusion strategies in order to closely mimic in vivo situation, we repeated the experimental conditions with lower concentration of gemcitabine in the IBIDI $\mu$-Slide 4 well $\mathrm{Ph}+$ ibiTreat, chip that was already established in a live-imaging fluidic system by our collegue (72). Again, the MDA-MB-231 cell line were imaged for 48 hours and analyzed as described previously.

Cellular behavior in the control, as well as when above mentioned treatment strategies were applied, is presented in Figure 20, where representative images show the initial and final cellular states. At the end of the experiment, in the case of the control, the cells covered the whole area of the well, meaning that they were continuously dividing during the 48-hour observation period. This is in contrast with all three treatment strategies, where statistically significant differences $(\mathrm{p}<0.05)$ were observed in respect to the control. Dead cells after all three applied drug administration approaches were detected at the end of the experiment, with slightly more dead cell area present after hydroxychloroquine pretreatment. Image analysis showed that the most effective treatment was hydroxychloroquine pretreatment followed by gemcitabine. Chloroquine pretreatment followed by gemcitabine and gemcitabine alone resulted in a similar response, where no statistically significant difference $(\mathrm{p}=0.998)$ was found. In these cases, constant increase in dead cell area, with a maximum value the end of the experiment can be seen (Figure 21.). The most efficient treatment strategy was when cells were treated with hydroxychloroquine with coadministrated gemcitabine, where the area occupied by dead cells increased by fivefold after the first 15 hours and continued to increase by the end of the experiment, with statistically significant differences compared to chloroquine pretreatment and gemcitabine administrated as a single agent. When cells were imaged under the same conditions in a 96-well plate (Figure 13B.) results were slightly different, where chloroquine pretreatment followed by gemcitabine resulted in more dead cells than gemcitabine alone. This slight variation in biological behavior under same conditions shows how different commercial tissue culture vessels and their material surface properties can make a difference in biological experiments and the importance of selecting and consistently using the same tissue culture vessel throughout an experiment. 


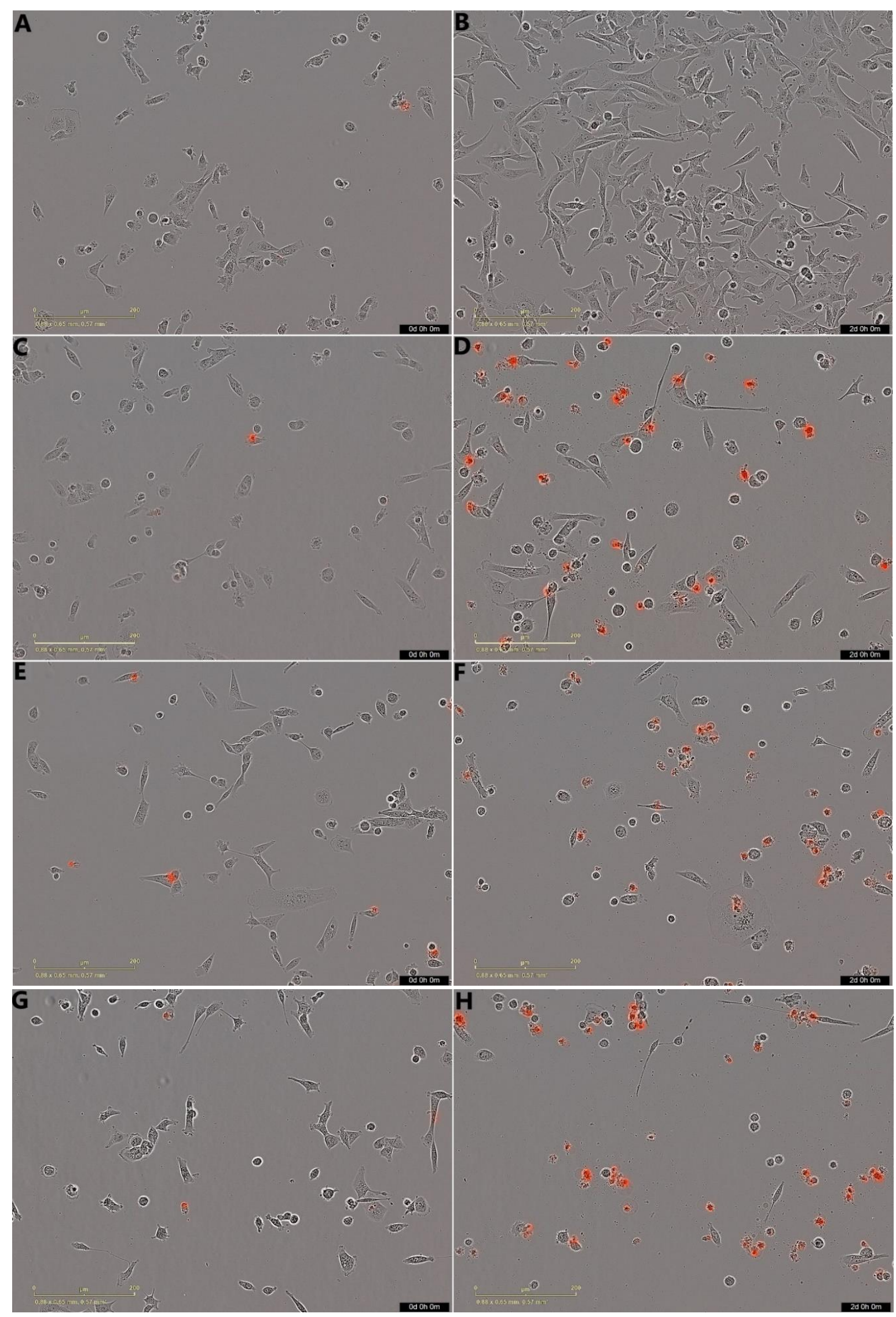

Figure 20. MDA-MB-231 cellular responses in a 4-well plate after different treatment strategy was applied. In this image sequence red dye (PI) is an indicator of dead cells. A) Control - no treatment - 0 hour; B) Control - no treatment-48 hour; C) $10 \mu \mathrm{M}$ gemcitabine - O hour; D) $10 \mu \mathrm{M}$ gemcitabine - 48 hours; E) Pretreatment with $30 \mu \mathrm{M}$ chloroquine $(6 \mathrm{~h})+10 \mu \mathrm{M}$ gemcitabine - 0 hour; F) Pretreatment with $30 \mu M$ chloroquine (6h) $+10 \mu M$ gemcitabine -48 hours: G) Pretreatment with $30 \mu M$ hydroxychloroquine $(6 h)+10 \mu M$ hemcitabine; H) Pretreatment with $30 \mu M$ hydroxychloroquine $(6 h)+10 \mu M$ gemcitabine. 
A

MDA-MB-231
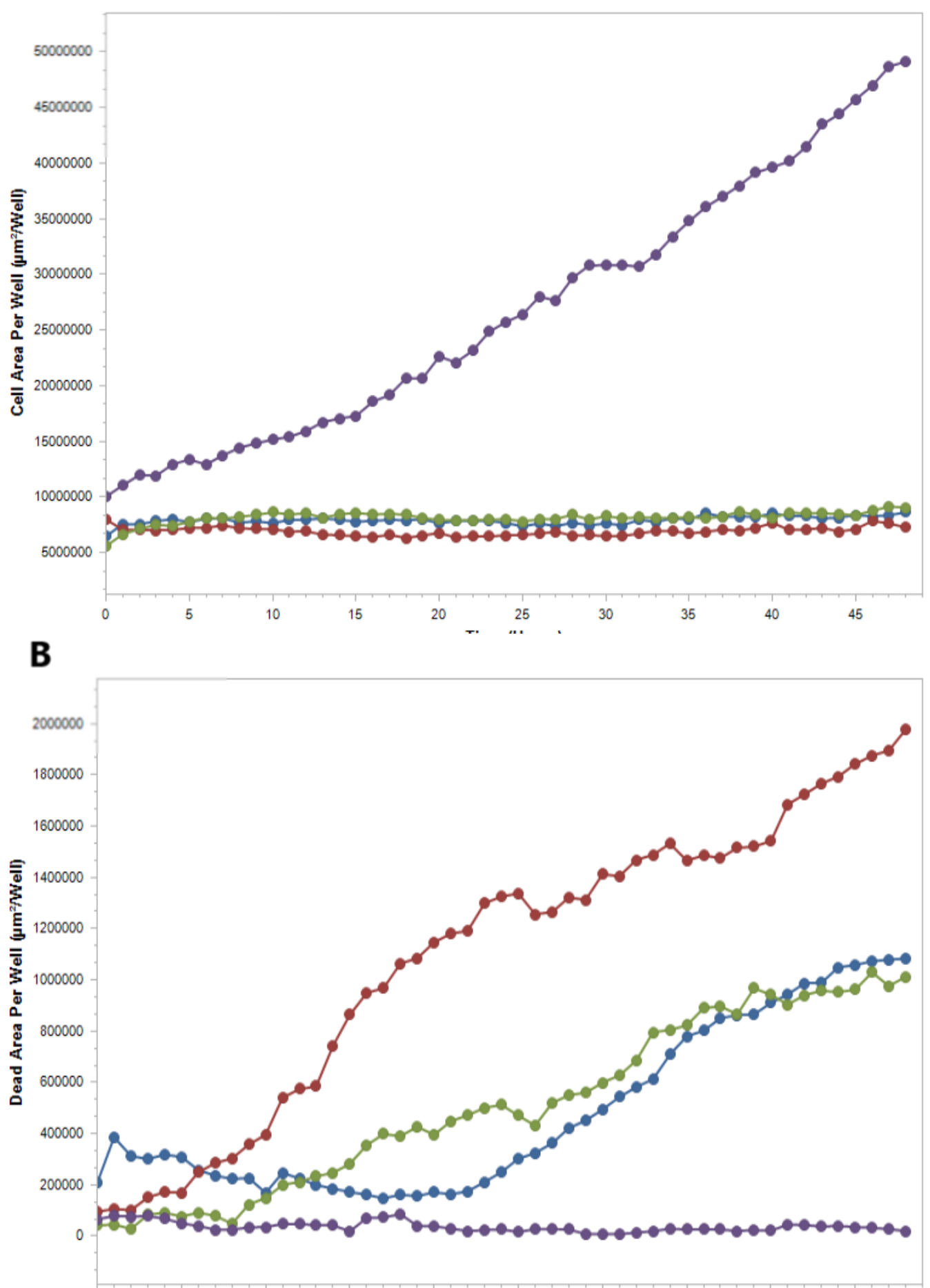

$C Q(30 \mu M)+$ 10 pM Gemcitabine HCQ $(30 \mu M)+$ 10 ulM Gemcitabine - 10 HM Gemcitabine Control. no treatment

Figure 21. Image analysis of TNBC MDA-MB-231 response to different treatment strategies followed for 48 hours. Cells were treated with $10 \mu \mathrm{M}$ gemcitabine or pretreated with $30 \mu \mathrm{M}$ chloroquine or hydroxychloroquine for 6 hours after which $10 \mu \mathrm{M}$ gemcitabine is added A) Cell population was assessed by analyzing cell area covered by cells over 48 hours. B) Dead area over 48 hours is determined by detecting red fluorescence per each well. 


\section{Discussion}

Triple negative breast cancer, characterized by absence of three main receptors and molecular targets (ER, PR, ERBB2) is still a challenge to treat due to lack of targeted therapy. Therefore, it is managed with chemotherapy drugs. Since TNBC is BC subtype that grows rapidly and results in metastasis and relapses, treatment failure and resistance are frequently reported. One of the biological processes that has been related with treatment resistance is autophagy, which is considered to be mechanism that leads tumor cells to overcome chemotherapy sensitivity, thus having protective role in many cancer types, including breast cancer. There is an increased interest in drug repositioning with goal to develop novel treatment strategies and overcome treatment resistance in TNBC. One of these drugs is chloroquine and its derivates which are able to block the late stage autophagy by preventing lysosome acidification. Combination of these agents with well-known chemotherapy drugs, that are leading to autophagy induction and promote tumor cell survival, is extensively researched, both, in vivo and in vitro and many preclinical studies demonstrated their sensitizing role to various chemotherapy drugs (61). Taking into consideration of the promising chloroquine and hydroxychloroquine therapeutic effect, we investigated antitumor effects of these agents in combination with conventional chemotherapy drugs in triple negative breast cancer cell line, MDA-MB-231. After administrating different drug combination the cells were visualized in real-time, by live-cell imaging for 48 hours in order to observe dynamic cellular behavior and morphology during different treatments.

Here, we observed significant increase in the amount of dead cells after chloroquine and hydroxychloroquine were administrated in combination with gemcitabine and camptothecin, compared to these drugs given as single agents. The most efficient drug strategy was combination of hydroxychloroquine with different concentrations of chemotherapy drugs, although no significant differences were observed between same approach with chloroquine and chemotherapy drugs was applied Moreover, even when these chemotherapy agents were administrated at lower concentrations after pretreatment with chloroquine and hydroxychloroquine, the area covered by dead cells was in constant increase. gemcitabine, although mostly first choice for pancreatic cancer treatment, is also being used for treating breast and non-small cell lung cancers and it acts as DNA 
synthesis inhibitor. This anticancer drug is also inducing apoptosis via caspase signaling (75). It has also been reported that gemcitabine is inducing tumor protective autophagy in MDA-MB-231 TNBC cell line (76). Another drug used in this research was camptothecin, which is well-known for inhibiting topoisomerase-I activity, causing double-strand DNA breakage in S-phase that results in apoptosis induction (77) when camptothecin was administrated to several breast cancer cell lines, including TNBC MDA-MB-231 it resulted in autophagy induction (78). Since many studies reported that autophagy may lead to the therapy resistance in TNBC, the research of chloroquine and hydroxychloroquine anti-cancer properties is rapidly expanding. One of the benefits for using these drugs is their safety and reduced toxicity, especially hydroxychloroquine that showed less side effects than chloroquine. Since chloroquine dose above $10 \mathrm{mg} / \mathrm{kg}(\sim 31 \mu \mathrm{M})$ is related to serious retinal toxicity, for our study we decided to use $30 \mu \mathrm{M}$ chloroquine, so that it is representing clinically realistic dose, which can be further applicable in translational research. Same dose was chosen for hydroxychloroquine, although, due to addition of hydroxyl group, hydroxychloroquine administration results in less side effects compared to chloroquine, so, this drug can be applied in higher doses. After examining drug combinations with higher concentration of chemotherapy agents we observed significant increase in the area of dead cells, detected by red fluorescent marker for dead cells, PI, we administrated lower doses of chemotherapy drugs and repeated the experiments with chloroquine and hydroxychloroquine pretreatments. Even though cell growth was reduced when cells were treated with lower concentration of gemcitabine and camptothecin alone, when these drugs were administrated after 6-hour chloroquine and hydroxychloroquine pretreatment significant difference in the area of dead cells was observed between these drugs combination and drugs alone. During 48-hours live cell imaging, stages of apoptotic cell dead, such as blebbing and apoptotic bodies, can be observed on obtained phase contrast images, mostly when combination of chloroquine or hydroxychloroquine with chemotherapy was administrated. Increased apoptosis was also observed in few other studies, when chloroquine and hydroxychloroquine were added to conventional chemotherapy treatment. When autophagy inhibitor were administrated together with osimertinib (79), gefitinib (80) Cyclophosphamide +Adriamycin (CA) (81) in MDA-MB-231 TNBC cell line it resulted in increased chemotherapeutics efficiency and cancer cell killing. These findings, together with our observation suggest that apoptosis and autophagy are opposed processes where increased level of one processes leads to decrease and inhibition of another. 
A study from 2014., performed by Chen et al, showed that gemcitabine administration is resulting in autophagy induction in MDA-MB-231 TNBC cell line. Here they demonstrated that autophagy induction is found to have tumor protecting role, leading to MDA-MB-231 loss of sensitivity to this chemotherapy drug. Moreover, when cells were pretreated with $5 \mu \mathrm{M}$ Chloroquine for one hour prior to gemcitabine administration significantly reduced cell viability and more dead cells were observed compared to gemcitabine administrated alone. They also found that the levels of anti-apoptotic Bcl-xL protein decreased whereas and the levels of p53 and pro-apoptotic Bax gene increased when chloroquine was administrated tin combination with gemcitabine, thus promoting apoptosis. This was not observed when gemcitabine was given as single agent (82). These results suggest that the gemcitabine-induced autophagy has protective role in this TNBC cell line and leads to apoptosis inhibition and cancer cell survival, thus showing that this treatment strategy might be effective therapeutic approach for TNBC. Chittaranjan et al., showed on both, in vivo and in vitro models, that epirubicin treatment leads to autophagy induction in MDA-MB-231 and SUM159 TNBC cell lines, leading to epirubicin resistance. When autophagy was inhibited in vitro with RNAi methods, and in vivo by administrating hydroxychloroquine in MDA-MB-231 xenograft mice, they noticed that this approach resulted in significant tumor growth and survival reduction, compared to single epirubicin treatment. Also, they derived epiruicin-resistant MDAMB-231 TNBC cell line in which increased basal autophagy was also observed, suggesting that chemotherapy resistance is maintained even in absence of the drug, in this case epirubicin. When these resistant cells were treated with epirubicin and chloroquine alone, as well as their combination, significant reduction in cell viability was observed (73). Another research from 2016 by Liang et al. reported impaired DNA damage repair and damage in mitochondrial structure in CSCs, as well as reduced metastatic ability in MDA-MB-231 TNBC cell line. The efficacy of carboplatin and reduction in tumor growth was also increased in carboplatin-resistant TNBC xenograft models. These findings are important for further development of new treatment strategies, prevention of metastasis and overall improvement of patients outcome since CSCs are found to play significant role in chemotherapy resistance and metastasis development (83).

Furthermore, it has been found that chloroquine does not only inhibit autophagy but has another anti-tumor properties, such as tumor vasculature normalization, thus improving tumor perfusion, reducing hypoxia, cancer cell invasion as well as improving the delivery and response to chemotherapeutics. This is also beneficial for metastatic cancer stage, where it leads to metastatic 
reduction and better drug efficiency (84). Vera-Ramirez et al. reported, both, in vivo and in vitro, that survival of dormant breast cancer cells is significantly decreased upon autophagy inhibition with hydroxychloroquine (85).

Although previously mentioned studies showed that autophagy exhibits tumor-promoting function and improves the chemotherapy efficacy, another studies reported that this is largely depended on cancer type, stage and chosen chemotherapy treatment. For example, Shen et al. used MDA-MB231 and MDA-MB-453 TNBC cell line to investigate the role of autophagy on chemotherapy response and found that, when autophagy was inhibited with 3-methyladenine, the docetaxel efficacy was increased while cisplatin cytotoxicity was impaired (86). This indicates that autophagy mode in the same cell line, but under different therapeutic strategy, is not the same. In another study, that involved MDA-MB-231 TNBC and MCF-7 ER+ xenograft mice models, reduction in tumor growth, after chloroquine, was observed in MDA-MB-231, while this was not observed in MCF-7 xenograft model, although autophagy was inhibited in both models. These results suggest that chloroquine potency is largely dependent on particular cell line (87).

So far, several clinical with autophagy inhibitors co-administrated with some well-known chemotherapy agents for different tumor types, including breast cancer, have been performed. Mostly these clinical trials are still ongoing and those that are completed were mostly with focus on safety of chloroquine and hydroxychloroquine in cancer treatment, which is found to be safe and tolerable with promising therapeutic role in cancer treatments. however some clinical trials with chloroquine were not that successful since the drug did not reach effective concentration. One of performed clinical trials involved hydroxychloroquine and ixabepilone for metastatic breast cancer (88) and chloroquine combination with taxane and taxane-like drugs (taxotere, abraxane, ixabepilone) (89).

Our study was performed in 2D static manner, where MDA-MB-231 TNBC cell line was treated with chloroquine, hydroxychloroquine and two chemotherapy drugs of choice, gemcitabine and camptothecin, alone or in combination. The cells were observed from first hour of treatment, till last (48. hour) by continuous live cell imaging, that involved fluorescent marker for following dead cells thus providing the value of area these cells occupied compared to live cells. As in studies mentioned before, our results also suggested the potential anti-cancer effect of autophagy inhibitors, chloroquine and hydroxychloroquine, when they were administrated together with 
chemotherapy drugs, which resulted in enhanced chemotherapy efficacy and increased cancer cell killing. Further studies will involve perfusion strategy for drug delivery as well as incorporation of autophagy and apoptosis markers for better and more detailed insight into the dynamic autophagy and apoptotic processes after delivery of chosen treatment strategy. Due to TNBC heterogeneity, the same treatment approach that was applied in this study will be applied to another TNBC cell lines with aim to support the results observed in MDA-MB-231 TNBC cell line. 


\section{Conclusion}

In our study, we observed that the autophagy inhibitors, chloroquine and hydroxychloroquine in combination with chemotherapy drugs, gemcitabine and camptotecin, enhance the chemotherapy efficacy in MDA-MB-231 TNBC cell line. The experiments were performed by continuous live cell imaging, powerful technique that allows observation of dynamic cellular behvaiour in realtime. This is particularly useful for monitoring cell responses to various treatment strategy since it allows deeper insight of cellular behaviour and morphological changes during cell response to administrated drugs. Even when chemotherapy drugs were administrated at lower doses in combination with chloroquine and, especially, hydroxychloroquine the cell growth was inhibited and cell dead enhanced. One of the mechanisms that is involved in chemotherapy resistance and reduced chemotherapy response is autophagy, which is mostly considered to have a tumorpromoting role in TNBC and allows cancer cells to evade apoptosis. Thus, we conclude that incorporation of these agents, that are found to inhibit autophagy, to conventional chemotherapy may be benefical for cancer treatment with potential to improve survival rates of breast cancer patients, especially in cancers lacking in efficient targeted therapy, such as TNBC. Administration of these drugs are proven to be safe and tolerable and growing number of preclinical and clinical data are encouraging further investigation of autophagy inhibitors and their potential anti-cancer role. Although we observed sensitizing effects to chemotherapy when chloroquine and hydroxychloroquine were applied, this is largely dependent on the cancer type and stage as well as administrated chemotherapy drug and its mechanism of action. In cancer where autophagy is not having protective role, this approach can even lead to worsen the treatment response. Therefore, further research with another TNBC cell lines as well as cell lines from another cancer types and utilization of autophagy and apoptosis markers are neccesary to elucidate the complex autophagy role in tumor cells. This may also confirm our findings and encourage further investigation of repurposing drugs for cancer treatment. 


\section{References}

1. Hudu, S. A., Alshrari, A. S., Syahida, A., \& Sekawi, Z. (2016). Cell Culture, Technology: Enhancing the Culture of Diagnosing Human Diseases. Journal of clinical and diagnostic research : JCDR, 10(3), DE01-DE5.

2. Sanyal, S. (2014). Culture and assay systems used for 3D cell culture. Corning, 9, 1-18.

3. Uysal, O., Sevimli, T., Sevimli, M., Gunes, S., \& Sariboyaci, A. E. (2018). Cell and Tissue Culture: The Base of Biotechnology. In Omics Technologies and Bio-Engineering (pp. 391-429). Academic Press.

4. Lucey, B. P., Nelson-Rees, W. A., \& Hutchins, G. M. (2009). Henrietta Lacks, HeLa cells, and cell culture contamination. Archives of pathology \& laboratory medicine, 133(9), 1463-1467.

5. Masters, J. R. (2002). HeLa cells 50 years on: the good, the bad and the ugly. Nature Reviews Cancer, 2(4), 315-319.

6. Aggarwal, B. B., Danda, D., Gupta, S., \& Gehlot, P. (2009). Models for prevention and treatment of cancer: problems vs promises. Biochemical pharmacology, 78(9), 1083-1094.

7. Pampaloni, F., Reynaud, E. G., \& Stelzer, E. H. (2007). The third dimension bridges the gap between cell culture and live tissue. Nature reviews Molecular cell biology, 8(10), 839845.

8. Kapałczyńska, M., Kolenda, T., Przybyła, W., Zajączkowska, M., Teresiak, A., Filas, V., Ibbs, M., Bliźniak, R., Łuczewski, Ł., \& Lamperska, K. (2018). 2D and 3D cell cultures a comparison of different types of cancer cell cultures. Archives of medical science : AMS, 14(4), 910-919. https://doi.org/10.5114/aoms.2016.63743

9. Hickman, J. A., Graeser, R., de Hoogt, R., Vidic, S., Brito, C., Gutekunst, M., \& van der Kuip, H. (2014). Three-dimensional models of cancer for pharmacology and cancer cell biology: capturing tumor complexity in vitro/ex vivo. Biotechnology journal, 9(9), 11151128.

10. Mirbagheri, M., Adibnia, V., Hughes, B. R., Waldman, S. D., Banquy, X., \& Hwang, D. K. (2019). Advanced cell culture platforms: a growing quest for emulating natural tissues. Materials Horizons, 6(1), 45-71. 
11. Cukierman, E., Pankov, R., Stevens, D. R., \& Yamada, K. M. (2001). Taking cell-matrix adhesions to the third dimension. Science, 294(5547), 1708-1712.

12. Ayuso, J. M., Virumbrales-Muñoz, M., Lacueva, A., Lanuza, P. M., Checa-Chavarria, E., Botella, P., ... \& Pardo, J. (2016). Development and characterization of a microfluidic model of the tumour microenvironment. Scientific reports, 6(1), 1-16.

13. American Cancer Society. (2018). American Cancer Society Facts \& Figures 2019.

14. Bray, F., Ferlay, J., Soerjomataram, I., Siegel, R. L., Torre, L. A., \& Jemal, A. (2018). Global cancer statistics 2018: GLOBOCAN estimates of incidence and mortality worldwide for 36 cancers in 185 countries. CA: a cancer journal for clinicians, 68(6), 394424.

15. Blows, F. M., Driver, K. E., Schmidt, M. K., Broeks, A., Van Leeuwen, F. E., Wesseling, J., ... \& Heikkilä, P. (2010). Subtyping of breast cancer by immunohistochemistry to investigate a relationship between subtype and short and long term survival: a collaborative analysis of data for 10,159 cases from 12 studies. PLoS medicine, 7(5).

16. Dai, X., Li, T., Bai, Z., Yang, Y., Liu, X., Zhan, J., \& Shi, B. (2015). Breast cancer intrinsic subtype classification, clinical use and future trends. American journal of cancer research, 5(10), 2929.

17. Waks, A. G., \& Winer, E. P. (2019). Breast cancer treatment: a review. Jama, 321(3), 288300.

18. Podo, F., Buydens, L. M., Degani, H., Hilhorst, R., Klipp, E., Gribbestad, I. S., ... \& Postma, G. J. (2010). Triple-negative breast cancer: present challenges and new perspectives. Molecular oncology, 4(3), 209-229.

19. Rakha, E. A., Reis-Filho, J. S., \& Ellis, I. O. (2008). Basal-like breast cancer: a critical review. Journal of clinical oncology, 26(15), 2568-2581.

20. Wahba, H. A., \& El-Hadaad, H. A. (2015). Current approaches in treatment of triplenegative breast cancer. Cancer biology \& medicine, 12(2), 106.

21. Liedtke, C., Mazouni, C., Hess, K. R., André, F., Tordai, A., Mejia, J. A., ... \& Cristofanilli, M. (2008). Response to neoadjuvant therapy and long-term survival in patients with triplenegative breast cancer. Journal of clinical oncology, 26(8), 1275-1281. 
22. Thomas, E. S., Gomez, H. L., Li, R. K., Chung, H. C., Fein, L. E., Chan, V. F., ... \& Xu, B. (2007). Ixabepilone plus capecitabine for metastatic breast cancer progressing after anthracycline and taxane treatment. Journal of Clinical Oncology, 25(33), 5210-5217.

23. Bauer, K. R., Brown, M., Cress, R. D., Parise, C. A., \& Caggiano, V. (2007). Descriptive analysis of estrogen receptor (ER)-negative, progesterone receptor (PR)-negative, and HER2-negative invasive breast cancer, the so-called triple-negative phenotype: a population-based study from the California cancer Registry. Cancer, 109(9), 1721-1728.

24. orlie, T.; Perou, C.M.; Tibshirani, R.; Aas, T.; Geisler, S.; Johnsen, H.; Hastie, T.; Eisen, M.B.; van de Rijn, M.; Jeffrey, S.S.; et al. Gene expression patterns of breast carcinomas distinguish tumor subclasses with clinical implications. Proc. Natl. Acad. Sci. USA 2001, 98, 10869-10874.

25. Gonzalez-Angulo, A. M., Timms, K. M., Liu, S., Chen, H., Litton, J. K., Potter, J., ... \& Hortobagyi, G. N. (2011). Incidence and outcome of BRCA mutations in unselected patients with triple receptor-negative breast cancer. Clinical Cancer Research, 17(5), 1082-1089.

26. Yao, H., He, G., Yan, S., Chen, C., Song, L., Rosol, T. J., \& Deng, X. (2017). Triplenegative breast cancer: is there a treatment on the horizon?. Oncotarget, 8(1), 1913.

27. Reinert, T., \& Barrios, C. H. (2015). Optimal management of hormone receptor positive metastatic breast cancer in 2016. Therapeutic advances in medical oncology, 7(6), 304320.

28. Davies, C., Pan, H., Godwin, J., Gray, R., Arriagada, R., Raina, V., ... \& Bradbury, J. (2013). Long-term effects of continuing adjuvant tamoxifen to 10 years versus stopping at 5 years after diagnosis of oestrogen receptor-positive breast cancer: ATLAS, a randomised trial. The Lancet, 381(9869), 805-816.

29. Tong, C. W., Wu, M., Cho, W., \& To, K. K. (2018). Recent advances in the treatment of breast cancer. Frontiers in oncology, 8, 227.

30. Baselga, J., Cortés, J., Kim, S. B., Im, S. A., Hegg, R., Im, Y. H., ... \& Clark, E. (2012). Pertuzumab plus trastuzumab plus docetaxel for metastatic breast cancer. New England Journal of Medicine, 366(2), 109-119.

31. Blum, J. L., Flynn, P. J., Yothers, G., Asmar, L., Geyer Jr, C. E., Jacobs, S. A., ... \& Gómez, H. L. (2017). Anthracyclines in Early Breast Cancer: The ABC Trials-USOR 06-090, 
NSABP B-46-I/USOR 07132, and NSABP B-49 (NRG Oncology). Journal of Clinical Oncology, 35(23), 2647.

32. Liedtke, C., Mazouni, C., Hess, K. R., André, F., Tordai, A., Mejia, J. A., ... \& Cristofanilli, M. (2008). Response to neoadjuvant therapy and long-term survival in patients with triplenegative breast cancer. Journal of clinical oncology, 26(8), 1275-1281.

33. Masuda, H., Baggerly, K. A., Wang, Y., Zhang, Y., Gonzalez-Angulo, A. M., MericBernstam, F., ... \& Symmans, W. F. (2013). Differential response to neoadjuvant chemotherapy among 7 triple-negative breast cancer molecular subtypes. Clinical cancer research, 19(19), 5533-5540.

34. Gluz, O., Liedtke, C., Gottschalk, N., Pusztai, L., Nitz, U., \& Harbeck, N. (2009). Triplenegative breast cancer-current status and future directions. Annals of Oncology, 20(12), 1913-1927.

35. Bianchini, G., Balko, J. M., Mayer, I. A., Sanders, M. E., \& Gianni, L. (2016). Triplenegative breast cancer: challenges and opportunities of a heterogeneous disease. Nature reviews Clinical oncology, 13(11), 674.

36. Maiti, R. (2014). Metronomic chemotherapy. Journal of pharmacology \& pharmacotherapeutics, 5(3), 186.

37. Kareva, I., Waxman, D. J., \& Klement, G. L. (2015). Metronomic chemotherapy: an attractive alternative to maximum tolerated dose therapy that can activate anti-tumor immunity and minimize therapeutic resistance. Cancer letters, 358(2), 100-106.

38. Bocci, G., \& Kerbel, R. S. (2016). Pharmacokinetics of metronomic chemotherapy: a neglected but crucial aspect. Nature Reviews Clinical Oncology, 13(11), 659.

39. André, N., Carré, M., \& Pasquier, E. (2014). Metronomics: towards personalized chemotherapy?. Nature reviews Clinical oncology, 11(7), 413.

40. Elmore, S. (2007). Apoptosis: a review of programmed cell death. Toxicologic pathology, 35(4), 495-516.

41. Xu, X., Lai, Y., \& Hua, Z. C. (2019). Apoptosis and apoptotic body: disease message and therapeutic target potentials. Bioscience reports, 39(1).

42. Taatjes, D. J., Sobel, B. E., \& Budd, R. C. (2008). Morphological and cytochemical determination of cell death by apoptosis. Histochemistry and cell biology, 129(1), 33-43. 
43. Abou-Ghali, M., \& Stiban, J. (2015). Regulation of ceramide channel formation and disassembly: Insights on the initiation of apoptosis. Saudi journal of biological sciences, 22(6), 760-772.

44. McIlwain, D. R., Berger, T., \& Mak, T. W. (2013). Caspase functions in cell death and disease. Cold Spring Harbor perspectives in biology, 5(4), a008656.

45. Wong, R. S. (2011). Apoptosis in cancer: from pathogenesis to treatment. Journal of Experimental \& Clinical Cancer Research, 30(1), 87.

46. Fulda, S. (2010). Evasion of apoptosis as a cellular stress response in cancer. International journal of cell biology, 2010.

47. Koff, J. L., Ramachandiran, S., \& Bernal-Mizrachi, L. (2015). A time to kill: targeting apoptosis in cancer. International journal of molecular sciences, 16(2), 2942-2955.

48. Talaiezadeh, A., Galehdari, H., \& Khodadadi, A. (2015). Time depended Bcl-2 inhibition might be useful for a targeted drug therapy. Cancer cell international, 15(1), 105.

49. Guo, J. Y., Teng, X., Laddha, S. V., Ma, S., Van Nostrand, S. C., Yang, Y., ... \& White, E. (2016). Autophagy provides metabolic substrates to maintain energy charge and nucleotide pools in Ras-driven lung cancer cells. Genes \& development, 30(15), 1704-1717.

50. Autophagy: process and function. Mizushima N Genes Dev. 2007 Nov 15; 21(22):286173.

51. Madrigal-Matute, J., \& Cuervo, A. M. (2016). Regulation of liver metabolism by autophagy. Gastroenterology, 150(2), 328-339.

52. Aita, V. M., Liang, X. H., Murty, V. V. V. S., Pincus, D. L., Yu, W., Cayanis, E., ... \& Levine, B. (1999). Cloning and genomic organization of beclin 1, a candidate tumor suppressor gene on chromosome 17q21. Genomics, 59(1), 59-65.

53. Flynn, A. L. B., \& Schiemann, W. P. (2019). Autophagy in breast cancer metastatic dormancy: Tumor suppressing or tumor promoting functions?. Journal of cancer metastasis and treatment, 5.

54. Amaravadi, R. K., Kimmelman, A. C., \& Debnath, J. (2019). Targeting autophagy in cancer: recent advances and future directions. Cancer discovery, 9(9), 1167-1181.

55. Sui, X., Chen, R., Wang, Z., Huang, Z., Kong, N., Zhang, M., ... \& Wang, X. (2013). Autophagy and chemotherapy resistance: a promising therapeutic target for cancer treatment. Cell death \& disease, 4(10), e838-e838. 
56. Al-Bari, M. A. A. (2015). Chloroquine analogues in drug discovery: new directions of uses, mechanisms of actions and toxic manifestations from malaria to multifarious diseases. Journal of Antimicrobial Chemotherapy, 70(6), 1608-1621.

57. McChesney, E. W. Animal toxicity and pharmacokinetics of hydroxychloroquine sulfate. Am. J. Med. 75, 11-18 (1983).

58. Pantziarka, P., Bouche, G., Meheus, L., Sukhatme, V., Sukhatme, V. P., \& Vikas, P. (2014). The repurposing drugs in oncology (ReDO) project. ecancermedicalscience, 8.

59. Pellegrini, P., Strambi, A., Zipoli, C., Hägg-Olofsson, M., Buoncervello, M., Linder, S., \& De Milito, A. (2014). Acidic extracellular pH neutralizes the autophagy-inhibiting activity of chloroquine: implications for cancer therapies. Autophagy, 10(4), 562-571.

60. Gurel-Gurevin, E., Kiyan, H. T., Esener, O. B. B., Aydinlik, S., Uvez, A., Ulukaya, E., ... \& Armutak, E. I. (2018). Chloroquine used in combination with chemotherapy synergistically suppresses growth and angiogenesis in vitro and in vivo. Anticancer research, 38(7), 4011-4020.

61. Verbaanderd, C., Maes, H., Schaaf, M. B., Sukhatme, V. P., Pantziarka, P., Sukhatme, V., ... \& Bouche, G. (2017). Repurposing Drugs in Oncology (ReDO) - chloroquine and hydroxychloroquine as anti-cancer agents. ecancermedicalscience, 11.

62. Maes, H., Kuchnio, A., Peric, A., Moens, S., Nys, K., De Bock, K., ... \& Vinckier, S. (2014). Tumor vessel normalization by chloroquine independent of autophagy. Cancer cell, 26(2), 190-206.

63. Wolpin, B. M., Rubinson, D. A., Wang, X., Chan, J. A., Cleary, J. M., Enzinger, P. C., ... \& Schrag, D. (2014). Phase II and pharmacodynamic study of autophagy inhibition using hydroxychloroquine in patients with metastatic pancreatic adenocarcinoma. The oncologist, 19(6), 637.

64. Jensen, E. C. (2013). Overview of live-cell imaging: requirements and methods used. The Anatomical Record: Advances in Integrative Anatomy and Evolutionary Biology, 296(1), 1-8.

65. Frigault, M. M., Lacoste, J., Swift, J. L., \& Brown, C. M. (2009). Live-cell microscopytips and tools. Journal of cell science, 122(6), 753-767.

66. Held P, Mongeon R. Advances in Live Cell Imaging Applications: Quantifying real time cellular responses from seconds to weeks. 2019. 
https://www.biotek.com/resources/webinars/advances-in-live-cell-imaging-applicationsquantifying-real-time-cellular-responses-from-seconds-to-weeks/. Accessed July 5, 2020.

67. Esner, M., Meyenhofer, F., \& Bickle, M. (2018). Live-cell high content screening in drug development. In High Content Screening (pp. 149-164). Humana Press, New York, NY.

68. Isherwood, B., Timpson, P., McGhee, E. J., Anderson, K. I., Canel, M., Serrels, A., ... \& Carragher, N. O. (2011). Live cell in vitro and in vivo imaging applications: accelerating drug discovery. Pharmaceutics, 3(2), 141-170.

69. Corning | Microplates | Assay Microplates | 96 well Microplates. https://ecatalog.corning.com/life-sciences/b2c/US/en/Microplates/Assay-Microplates/96Well-Microplates/Falcon\%C2\%AE-96-well-Polystyrene-Microplates/p/353072. Accessed: July 7, 2020.

70. Essen BioScience. Incucyte ${ }^{\circledR}$ S3 Live-Cell Analysis System. https://www.essenbioscience.com/en/products/incucyte/incucyte-s3/. Accessed July 7, 2020.

71. Etti, I. C., Abdullah, R., Kadir, A., Hashim, N. M., Yeap, S. K., Imam, M. U., ... \& Waziri, P. (2017). The molecular mechanism of the anticancer effect of Artonin E in MDA-MB 231 triple negative breast cancer cells. PLoS One, 12(8), e0182357.

72. Ruarte D. Optimization of long-term Breast Cancer Cell Culture using live Imaging in an automated Perfusion System, 2020.

73. Chittaranjan, S., Bortnik, S., Dragowska, W. H., Xu, J., Abeysundara, N., Leung, A., ... \& Yapp, D. T. (2014). Autophagy inhibition augments the anticancer effects of epirubicin treatment in anthracycline-sensitive and-resistant triple-negative breast cancer. Clinical Cancer Research, 20(12), 3159-3173.

74. Zhang, Y., Cao, Y., Sun, X., Feng, Y., Du, Y., Liu, F., ... \& Jin, F. (2017). Chloroquine (CQ) exerts anti-breast cancer through modulating microenvironment and inducing apoptosis. International immunopharmacology, 42, 100-107.

75. de Sousa Cavalcante, L., \& Monteiro, G. (2014). Gemcitabine: metabolism and molecular mechanisms of action, sensitivity and chemoresistance in pancreatic cancer. European journal of pharmacology, 741, 8-16. 
76. Shen, P., Chen, M., He, M., Chen, L., Song, Y., Xiao, P., ... \& Wang, Q. (2016). Inhibition of ER $\alpha / E R K / P 62$ cascades induces "autophagic switch" in the estrogen receptor-positive breast cancer cells exposed to gemcitabine. Oncotarget, 7(30), 48501.

77. Lin, C. S., Chen, P. C., Wang, C. K., Wang, C. W., Chang, Y. J., Tai, C. J., \& Tai, C. J. (2014). Antitumor effects and biological mechanism of action of the aqueous extract of the Camptotheca acuminata fruit in human endometrial Carcinoma cells. Evidence-Based Complementary and Alternative Medicine, 2014.

78. Abedin, M. J., Wang, D., McDonnell, M. A., Lehmann, U., \& Kelekar, A. (2007). Autophagy delays apoptotic death in breast cancer cells following DNA damage. Cell Death \& Differentiation, 14(3), 500-510.

79. Fleisher, B., Mody, H., Werkman, C., \& Ait-Oudhia, S. (2019). Chloroquine sensitizes MDA-MB-231 cells to osimertinib through autophagy-apoptosis crosstalk pathway. Breast Cancer: Targets and Therapy, 11, 231.

80. Liu, Z., He, K., Ma, Q., Yu, Q., Liu, C., Ndege, I., ... \& Yu, Z. (2017). Autophagy inhibitor facilitates gefitinib sensitivity in vitro and in vivo by activating mitochondrial apoptosis in triple negative breast cancer. PLoS One, 12(5), e0177694.

81. Lefort, S., Joffre, C., Kieffer, Y., Givel, A. M., Bourachot, B., Zago, G., ... \& Camonis, J. (2014). Inhibition of autophagy as a new means of improving chemotherapy efficiency in high-LC3B triple-negative breast cancers. Autophagy, 10(12), 2122-2142.

82. Chen, M., He, M., Song, Y., Chen, L., Xiao, P., Wan, X., ... \& Shen, P. (2014). The cytoprotective role of gemcitabine-induced autophagy associated with apoptosis inhibition in triple-negative MDA-MB-231 breast cancer cells. International journal of molecular medicine, 34(1), 276-282.

83. Liang, D. H., Choi, D. S., Ensor, J. E., Kaipparettu, B. A., Bass, B. L., \& Chang, J. C. (2016). The autophagy inhibitor chloroquine targets cancer stem cells in triple negative breast cancer by inducing mitochondrial damage and impairing DNA break repair. Cancer letters, 376(2), 249-258.

84. Maes, H., Kuchnio, A., Peric, A., Moens, S., Nys, K., De Bock, K., ... \& Vinckier, S. (2014). Tumor vessel normalization by chloroquine independent of autophagy. Cancer cell, 26(2), 190-206. 
85. Vera-Ramirez, L., Vodnala, S. K., Nini, R., Hunter, K. W., \& Green, J. E. (2018). Autophagy promotes the survival of dormant breast cancer cells and metastatic tumour recurrence. Nature communications, 9(1), 1-12.

86. Shen, M., Duan, W. M., Wu, M. Y., Wang, W. J., Liu, L., Xu, M. D., ... \& Gong, F. R. (2015). Participation of autophagy in the cytotoxicity against breast cancer cells by cisplatin. Oncology reports, 34(1), 359-367.

87. Maycotte, P., Gearheart, C. M., Barnard, R., Aryal, S., Levy, J. M. M., Fosmire, S. P., ... \& Thorburn, A. (2014). STAT3-mediated autophagy dependence identifies subtypes of breast cancer where autophagy inhibition can be efficacious. Cancer research, 74(9), 25792590.

88. National Library of Medicine (U.S.). (2005, February - ). Ixabepilone and Hydroxychloroquine in Treating Patients With Metastatic Breast Cancer. Identifier. NCT00765765. https://clinicaltrials.gov/ct2/show/NCT00765765

89. National Library of Medicine (U.S.). (2011, October - ). Chloroquine With Taxane Chemotherapy for Advanced or Metastatic Breast Cancer After Anthracycline Failure (CAT) (CAT) Identifier. NCT01446016. https://clinicaltrials.gov/ct2/show/NCT01446016 